\title{
Capítulo 3 - Democracia e desigualdade dados e relação descritiva
}

\author{
Ivan Filipe de Almeida Lopes Fernandes
}

\section{SciELO Books / SciELO Livros / SciELO Libros}

FERNANDES, I.F.A.L. Democracia e desigualdade: dados e relação descritiva. In: $A$ democracia reduz a desigualdade econômica? Um estudo sobre as possibilidades de construção de uma sociedade mais igual por meio da democracia [online]. São Bernardo do Campo, SP: Editora UFABC, 2017, pp. 107173. ISBN: 978-85-68576-79-3. https://doi.org/10.7476/9788568576793.0004.

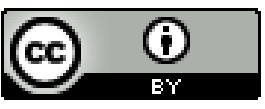

All the contents of this work, except where otherwise noted, is licensed under a Creative Commons Attribution 4.0 International license.

Todo o conteúdo deste trabalho, exceto quando houver ressalva, é publicado sob a licença Creative Commons Atribição 4.0.

Todo el contenido de esta obra, excepto donde se indique lo contrario, está bajo licencia de la licencia $\underline{\text { Creative }}$ Commons Reconocimento 4.0. 


\section{Capítulo 3}

\section{Democracia e desigualdade: dados e relação descritiva}

Este capítulo está dividido em 5 seções e nele iniciamos a análise empírica da relação entre democracia e desigualdade. Nas duas primeiras seções apresentamos os conceitos a partir dos quais definimos e mensuramos democracia e desigualdade. Na terceira seção apresentamos os dados descritivos da relação entre estas duas variáveis. Um importante achado é que no período histórico abrangido pelos dados - entre os anos 1960 e a primeira década do século XXI - o usual diagnóstico sobre o crescente e preocupante avanço da desigualdade econômica pelo mundo, tão debatido na literatura contemporânea, não encontra respaldo nos dados, ainda que seja possível observar um abrupto crescimento da desigualdade entre as democracias consolidadas e mais desenvolvidas a partir da década de $1980^{54}$.

$\mathrm{Na}$ quarta seção apresentamos novas informações descritivas e discutimos a relação entre democracia e desigualdade em uma visão de longo prazo, iniciada ainda no século XIX. Nesta visão de longo prazo, apresentada no Gráfico 12,

\footnotetext{
${ }^{54}$ Um pequeno crescimento da média da desigualdade econômica entre os países entre 1970 e 2005 é indicado no Gráfico 6, enquanto no Gráfico 7 há uma singela tendência decrescente para o mesmo período.
} 
fica claro que houve uma forte redução da média de desigualdade econômica entre os países na $1^{\circ}$ metade do século XX, acompanhado de uma reversão desta tendência com crescimento até 1990, ainda que este aumento seja menos abrupto do que a queda anterior. Obviamente um problema inerente ao esforço empírico de tratar de dados econômicos que voltam tanto no tempo decorre do fato que as mensurações de desigualdade são menos válidas e confiáveis do que os dados mais recentes, obtidos por meio de metodologias modernas como, por exemplo, surveys de renda. Por fim, na quinta e última seção apresentamos os dados das variáveis controles utilizadas na pesquisa e concluímos o capítulo.

\subsection{Dados e definições de democracia}

Nesta pesquisa trabalhamos com o conceito dahlsiano de que democracia é o regime no qual os governos perdem eleições livres, competitivas, certas e justas e deixam o poder, dando espaço político para a oposição. Em outras palavras, é o regime político no qual existe competição entre os diferentes atores que possuem interesses em acessar e ocupar os loci institucionais de poder. E esta competição é realizada dentro de uma arena institucionalizada e com regras que são respeitadas por todos os jogadores. Aqueles que detêm o poder momentâneo são obrigados por essas próprias regras a entregar o poder político a outro grupo caso o último seja vitorioso nas eleições.

Abstemo-nos de qualquer tipo de discussão conceitual a respeito de se o conteúdo do termo democracia deve indicar apenas um procedimento de escolha das lideranças políticas ou requer elementos substantivos associados aos procedimentos 
eleitorais. Posto de outra forma, para os leitores que consideram a definição minimalista de democracia muito pouco exigente e entendem que este construto deveria abranger outros elementos substantivos, a nossa pesquisa tenta estimar o impacto que a competição política livre e aberta tem sobre a desigualdade econômica.

Além do debate conceitual, existem inúmeras propostas de mensuração dos regimes políticos que foram elaboradas ao longo do tempo para medir os efeitos da democracia sobre uma gama enorme de variáveis e também sobre quais são os principais determinantes dos processos de democratização e consolidação democrática. Mas, conforme demonstramos nos próximos parágrafos, a única medida que assume ipsis litteris a nossa definição de democracia como competição política, justificada pelas elaborações teóricas do capítulo anterior, é a concepção minimalista de Alvarez, Cheibub, Limongi e Przeworski (1996) e atualizada por Cheibub, Gandhi e Vreeland (2010), de agora em diante indicada como CGV.

Existem outras duas medidas de regime político largamente utilizadas na literatura: a medida elaborada pela Freedom House (FH) sobre direitos políticos e liberdades civis (BOLLEN, 1980) e a medida do POLITY IV sobre características diversas dos regimes políticos (MARSHALL et al., 2002). Essas três medidas cobrem um grande número de países ao longo de um extenso número de anos. Mas, segundo os próprios Cheibub, Gandhi e Vreeland (2010), se diferem em três características fundamentais, que justificam a nossa opção pelo CGV. As três diferenças são referentes à ${ }^{55}$ :

55 Apresentamos brevemente os pontos que justificam a nossa escolha pelo CGV. Para uma análise mais pormenorizada de suas características ver 
i) Diferentes concepções de democracia;

ii) Natureza do tipo de dado utilizado nos indicadores de regime político;

iii) Tipo de mensuração realizada.

No que toca à concepção de democracia subjacente ao esforço de mensuração, apenas o CGV assume uma definição estritamente procedimental e minimalista de um regime político. As medidas da FH e do POLITY IV possuem uma concepção substantiva do processo, referindo-se concomitantemente à exigência de um procedimento de escolha das lideranças por meio de eleições livres, competitivas, certas e justas e também questões de cunho extraprocedimental, como, por exemplo, a ausência de violações de direitos civis ou mesmo o respeito e responsividade do governo aos interesses dos cidadãos e/ou o controle sociopolítico do Estado. Isto é, enquanto na visão do CGV a democracia é apenas o método de escolha dos dirigentes políticos, as outras medidas entendem que a competição é necessária, mas insuficiente para definir os contornos exatos da democracia.

Como propomos que as eleições competitivas sejam o fundamento do diferencial qualitativo que justifica quando e em quais condições surgem as diferenças entre regimes políticos democráticos e não democráticos sobre a desigualdade econômica, a proposição minimalista de CGV torna-se, sem sombra de dúvidas, a mais adequada para o teste da hipótese de que os efeitos da democracia são heterogêneos. Como o FH ou o POLITY IV incluem elementos além das fronteiras eleitorais, caso optássemos por estas escalas, tornar-se-ia muito

Cheibub, Gandhi e Vreeland (2010). Em Elkins (2000) é feita importante crítica às escolhas metodológicas do CGV. 
mais difícil apontar qual é o tipo de conexão teórica entre o regime democrático e a desigualdade econômica.

O segundo ponto que embasa a nossa opção pelo CGV decorre da maior confiabilidade ${ }^{56}$ de seus dados, pois as informações coletadas para diferenciar o que seja uma democracia de um regime não democrático são objetivas e as regras de codificação e manipulação dos dados são claras. Isto porque o CGV se baseia em eventos políticos cujas ocorrências não são difíceis de determinar, tais como a realização de eleições, a existência de mais de um partido político e mudanças partidárias na liderança do governo. Já a atribuição dos valores da FH é realizada por especialistas cuja codificação nem sempre é evidente ao usuário do banco de dados e a mensuração realizada pelo POLITY IV, ainda que objetiva, requer a observação de minúcias do dia a dia da política do país analisado.

Por fim, a mensuração dicotômica do CGV elimina as dificuldades e ambiguidades inerentes às propostas policotômicas do FH e do POLITY IV. A agregação dos indicadores destas escalas torna difícil a identificação clara de quais são os verdadeiros significados de seus diferentes pontos na escala. Por sua vez, a regra de agregação aditiva do CGV elimina a possibilidade que diferentes combinações de características institucionais e eventos políticos indiquem um mesmo valor de democracia. Posto isto, o formato policotômico trazido pelo POLITY IV e pela FH não é mais informativo, tal como à primeira vista é pensado por se aproximar mais de um contínuo de democracia. Isto porque ambas não indicam de

\footnotetext{
56 Confiabilidade é a medida que mensura o quão os resultados de uma determinada medida são repetidos de maneira similar sob condições consistentes. Isto é, o quanto a técnica de mensuração é precisa. Quanto menor for a probabilidade de erro que a recontagem do dado pode ter, mais confiável é a medida.
} 
maneira objetiva o que significa no mundo real o avanço em um ponto de suas respectivas escalas ${ }^{57}$.

Desta maneira, os problemas de não classificação de regimes “intermediários” pelo CGV são minimizados, uma vez que os critérios de definição deste "tipo" de regime pelo POLITY IV e pela FH são obscuros e a partir de informações não objetivas. Ademais toda a literatura da transitologia encara a diferenciação entre um regime autoritário e um regime democrático como um traço qualitativo profundo e não apenas uma gradação em uma escala imaginária de competição política.

\subsubsection{Democracia como processo}

A democracia é um regime no qual as posições centrais de governo são preenchidas segundo os resultados de eleições competitivas, livres, certas e justas. Esta definição possui dois elementos centrais: posições centrais de governo e competição política por meio de eleições. As posições centrais de governo são os órgãos fundamentais da vida política de qualquer comunidade política - os postos responsáveis pela criação e pela execução das leis. Assim, para um regime ser democrático é necessário que o preenchimento das posições no corpo legislativo e no corpo executivo do governo seja realizado por meio de um método eleitoral. E a competição política indica que o método eleitoral deve possibilitar a livre competição dos agentes políticos, de forma que cidadãos opositores aos que ocupam o governo possuam chances reais de tomar o poder pela via eleitoral.

57 O POLITY IV mensura democracia em uma escala de 21 pontos que vão desde -10 (menos democrático) a +10 (mais democrático), enquanto a Freedom House propõe duas escalas de 7 pontos para mensurar, respectivamente, direitos políticos e liberdades civis. 
As eleições necessitam de 3 condições fundamentais para cumprir com seu papel de mecanismo competitivo de definição das posições centrais do governo: i) incerteza ex ante de quem seja o vitorioso; ii) irreversibilidade ex post do resultado; e iii) repetitividade das eleições. Estas três características fundamentais determinam se as eleições são competitivas, livres, certas e justas. Isto porque a condição $\mathbf{i}$ indica que o jogo político é aberto e seus resultados não são pré-definidos. A condição ii indica que não é possível que o governo reverta uma eleição perdida, fraudando ou anulando uma vitória da oposição. E, por fim, a condição iii indica que o jogo eleitoral repete-se ao longo do tempo, impedindo que apenas um grupo tenha o seu poder congelado, além de abrir a possibilidade para que o perdedor trabalhe com a expectativa de que é possível esperar as próximas eleições para reverter numa batalha eleitoral futura a competição política perdida no presente.

Para operacionalizar empiricamente essa definição procedimental e minimalista de democracia são estabelecidas por Alvarez, Cheibub, Limongi e Przeworski (1996) e repetidos por Cheibub, Gandhi e Vreeland (2010) quatro critérios objetivos. Caso um desses não seja atendido, o país é considerado como não democrático naquele ano.

1. Chefe do Executivo escolhido por meio de uma eleição popular ou por um corpo eleitoral eleito popularmente;

2. Legislativo eleito popularmente;

3. Mínimo de dois partidos competindo nas eleições;

4. Alternância de poder dentro das leis eleitorais nas quais a competição política ocorre.

As eleições que ocorrem em sistema unipartidário não são consideradas eleições democráticas, assim como as eleições que ocorrem de maneira aparentemente aberta, mas 
cujos resultados foram ignorados pelo governo no momento no qual o partido de sustentação do Poder Executivo perdeu apoio eleitoral. A implementação da regra da alternância no poder busca eliminar a possibilidade de se considerar erroneamente regimes autoritários com algum grau de competição eleitoral como um regime democrático de fato. Contudo, inevitavelmente esta regra da alternância produz um erro de mensuração esperado: ela não diferencia os regimes políticos que terão alternância de poder no futuro daqueles que o governo fraudará ou anulará as eleições caso a oposição política seja vitoriosa nas urnas. A opção do CGV nesses casos foi assumir uma posição mais conservadora face aos dados e indicar que esses dois tipos de situação configuram regimes não democráticos, corrigindo os dados apenas no momento em que a oposição obtém sua primeira vitória eleitoral e a história demonstra cabalmente se a regra eleitoral é ou não violada.

\subsubsection{Uma medida alternativa de competição política}

Descartamos de maneira peremptória o uso da escala elaborada pela Freedom House, pois além de ser pouco clara e muito subjetiva em sua métrica de mensuração, a concepção de democracia adotada pela instituição se afasta da definição minimalista que utilizamos nesta pesquisa. A FH compreende que democracia abarca mais elementos do que a mera existência de eleições livres, competitivas e justas, embora não fiquem claros quais são os conceitos substantivos tratados como mais caros na concepção de democracia da instituição. Por outro lado, ainda que o POLITY IV seja uma escala de democracia que também exija qualidades substantivas, ele é composto pela agregação de uma série de subescalas que mensuram diferentes 
atributos de um regime democrático. Estas, por sua vez, são avaliadas em critérios objetivos, estando as mensurações de suas subescalas disponíveis e desagregadas para um uso mais parcimonioso dos dados.

A escala final de democracia-ditadura no POLITY IV é uma escala aditiva de 21 pontos derivados de 5 subescalas originárias: a) competitividade da participação política; b) abertura no recrutamento do Poder Executivo; c) competitividade no recrutamento do Executivo; d) constrangimentos ao Chefe do Executivo; e) regulação da participação.

Dentre estas cinco, as duas mais adequadas para a discussão de nosso objeto de pesquisa são a primeira, competitividade da participação política, e a terceira, competitividade no recrutamento do Executivo, pois ambas mensuram importantes facetas do fenômeno político que tentamos contemplar na pesquisa: a existência de projetos políticos competitivos que concorrem pela aprovação da população por meio de eleições.

Nas próprias palavras dos organizadores do POLITY IV, a subescala de competitividade da participação mensura: "a extensão em que preferências alternativas por políticas e por lideranças podem ser perseguidas na arena política" (MARSHALL; JAGGERS; GURR, 2011, p. 26). Já a subescala de competitividade do recrutamento do Executivo é definida como:

A extensão em que os mecanismos de progresso profissional dão aos subordinados chances iguais de se tornarem mandatários. Por exemplo, a seleção do chefe do executivo por meio de eleições populares entre dois ou mais partidos ou candidatos viáveis é considerada como competitiva. (MARSHALL; JAGGERS; GURR, 2011, p. 21).

A competitividade da participação política é mensurada nas seguintes cinco categorias (5) competitiva, (4) transicional, 
(3) faccional, (2) suprimida, (1) repressiva, sendo que a competição política competitiva é definida como aquela na qual existem:

Grupos políticos relativamente estáveis e duradouros que regularmente competem pela influência política no nível nacional; os grupos e coligações dominantes regular e, voluntariamente, transferem o poder central para grupos concorrentes. A competição entre os grupos raramente envolve coerção ou interrupção violenta. Pequenos partidos ou grupos políticos podem ser restringidos no padrão competitivo. (MARSHALL; JAGGERS; GURR, 2011, p. 27).

Essa definição se aproxima da ideia da natureza competitiva da competição eleitoral, uma vez que na arena eleitoral são postos em disputa diferentes projetos políticos sobre o país, incluindo a possibilidade de que estes projetos tratem de alguma forma sobre como deve ser regulada a relação entre o mercado e a desigualdade econômica.

Já a escala de competitividade do recrutamento do Executivo é mensurada nas seguintes três categorias (3) eleições; (2) dual/transicional e (1) seleção, sendo que o recrutamento eleitoral é definido como aquele método de escolha no qual "os chefes do executivo são tipicamente escolhidos por meio de eleições competitivas entre dois ou mais candidatos principais (as eleições podem ser populares ou realizadas por uma assembleia eleita popularmente)" (MARSHALL; JAGGERS; GURR, 2011, p. 22). Essa definição também se aproxima da ideia da natureza competitiva da competição eleitoral, uma vez que discutimos a hipótese de que as eleições livres, competitivas e justas são o principal mecanismo regulador da relação entre a democracia e desigualdade econômica. 
Posto isso, propomos três outras formas de mensuração da competição política baseadas nestas duas subescalas do POLITY IV: a) classificação dicotômica na qual os regimes políticos cuja participação política é qualificada como competitiva são considerados como democrático e todos os outros são considerados como autoritários; b) classificação dicotômica na qual o método de recrutamento eleitoral dos chefes do Executivo é considerado como democráticos e todos os outros são considerados como autoritários e c) uma interação entre as duas variáveis, sendo considerado democrático apenas os regimes com participação política competitiva e recrutamento do Executivo pela via eleitoral. Denominamos a primeira variável como Participação, a segunda como Recrutamento e a terceira como Competição.

\subsection{Dados e definições de desigualdade}

Utilizamos como medida básica da desigualdade econômica nacional o Coeficiente de GINI, que é uma medida de dispersão estatística desenvolvida pelo estatístico e sociólogo italiano Corrado Gini (1912) para representar a distribuição de renda dentro de uma dada população. O GINI mensura a desigualdade entre os valores de duas distribuições de frequência, no caso a distribuição de renda e a distribuição de habitantes de um país. Um coeficiente de GINI igual a zero indica a perfeita equidade entre ambas, a renda é igualmente distribuída entre a população - todos recebem a mesma renda. Já um GINI de 1 (ou 100\%) indica a máxima desigualdade entre os possíveis valores de renda - apenas uma pessoa detém toda a renda e todos os outros obtém zero. Optamos por essa 
medida, pois além de ser a mais tradicional na literatura, ela também é sensível às modificações ocorridas em todo o escopo da distribuição de renda.

Existem outras medidas que mensuram diferentes aspectos da desigualdade, como, por exemplo, o papel da fração da renda que é controlada pela elite econômica. $\mathrm{O}$ vasto estudo de Piketty (2014) sobre o aumento da desigualdade nas economias mais avançadas baseia-se fortemente em dados a respeito do controle da renda e da riqueza dos $10 \%$ e $1 \%$ mais ricos ${ }^{58}$. Esta medida, que é bastante adequada para captar os efeitos do papel especial exercido pela elite econômica na economia capitalista, não é apropriada para mensurar efeitos agregados na desigualdade que ocorrem na calda direita da distribuição (entre os mais pobres e as classes medianas) e nem fenômenos relacionados à redistribuição entre os mais pobres e as classes medianas ${ }^{59}$.

Além da definição conceitual da medida de desigualdade, outra dificuldade importante é que a própria forma de mensuração do coeficiente de GINI ainda não é um consenso na literatura. Os dados disponíveis na maioria dos casos são obtidos por meio de inúmeros e discrepantes métodos, sendo o mais comum o uso de surveys de renda ou consumo. Contudo mesmo nas surveys, os métodos de conceituação, amostragem, codificação e tratamento dos dados nem sempre são convergentes e consistentes ao longo do tempo e entre diferentes países. Assim, as técnicas de mensuração variaram em demasia ao longo dos eixos transversal e temporal, tornando conceitualmente

\footnotetext{
${ }^{58}$ Para uma discussão de diferentes medidas sobre a desigualdade ver (DE MAIO, 2007).

59 Além do limite operacional decorrente do fato que tais medidas ainda não foram compiladas para um grande número de países.
} 
inconsistentes comparações cruas. Tais atritos conceituais acabam aumentando a probabilidade de erro e enviesando as análises comparadas sobre a desigualdade econômica.

Outra dificuldade adicional decorre do fato de que boa parte das observações e medidas de desigualdade entre países e ao longo do tempo se baseiam em surveys realizadas ocasionalmente, pois poucos incluem em suas estatísticas nacionais a mensuração anual do GINI. E como os dados tem origem em surveys, não é possível recodificar e reparar possíveis defeitos originais e nem complementa-los retrospectivamente por intermédio dos mesmos métodos com os quais foram criados, uma vez que não é possível repetir as entrevistas realizadas no passado. Nas palavras de Galbratih (2012, p. 20):

Não se pode fazer uma survey retrospectiva; não há maneira de voltar para a casa do indivíduo e perguntar qual era sua renda de cinco, dez ou vinte anos atrás. Assim, as lacunas de informações não podem ser preenchidas [...].

Diante desses enormes problemas de comparabilidade dos dados, em 1996 Klaus Deininger e Lyn Squire (1996) publicaram no The World Bank Economic Review um banco de dados no qual fora compilado um conjunto bastante grande de surveys sobre disparidade de renda e de gastos com indicações dos pontos de dados que atendiam a certos critérios de "alta qualidade", oferecendo o primeiro banco em painel e abrangente com 682 observações de países-anos desde 1947, dentre uma oferta de mais de 2600 observações de qualidade questionável ${ }^{60}$. Este banco foi um formidável estímulo aos

\footnotetext{
${ }^{60}$ Esses critérios são: cobertura abrangente de todos os tipos de renda, incluindo rendimentos em espécie e não salariais, como pensões e aluguéis; cobertura
} 
estudos sobre a desigualdade econômica e dezenas de trabalhos passaram a usá-lo ${ }^{61}$.

Esforços para expandir o projeto de Deininger e Squire - DS continuaram, principalmente na UNU-WIDER - World Institute for Development Economics Research da Universidade das Nações Unidas em Helsinki. Mesmo com a maior abrangência dos dados coletados, a estrutura metodológica manteve-se e as regras de compilação do DS permaneceram. A UNU-WIDER organizou um banco com 5314 observações de 160 países denominado como World Income Inequality $\mathrm{Da}$ tabase - WIID. Contudo alguns pontos são repetidos para alguns países-anos e abrangem diferentes métodos e conceitos de desigualdade, não constituindo um banco de dados que possa ser usado sem um tratamento estatístico de padronização adequado.

Não obstante o crescente número de observações, a cobertura continuou esparsa e desbalanceada, com poucos dados com "alta qualidade" para boa parte do mundo em desenvolvimento. Milanovic (2002) apontou que o principal problema das medidas de desigualdade do DS e do UNU-WIDER, apesar de todas as virtudes levantadas, decorre da grande quantidade de dados omitidos e da excessiva interpolação feita nos trabalhos que o adotaram.

Atkinson e Brandolini (2001) apontaram ainda que as medidas do DS e da UNU-WIDER são baseadas em diferentes definições conceituais de renda, unidades de referência e procedimentos de pesquisa, que não podem ser totalmente

abrangente da população, incluindo famílias urbanas e rurais; e que tenham tido como unidade básica os domicílios (DEININGER; SQUIRE, 1996).

${ }^{61} \mathrm{O}$ artigo inaugural de Deininger e Squire possui cerca de 3329 citações no Google Scholar. Acesso em: 11 nov. 2016. 
reconciliados com o outro, mesmo na filtragem de "alta qualidade". Isso porque, a despeito da medida de desigualdade do DS e da UNU-WIDER seja o GINI, não existe uma base métodológica comum. Em particular, diferenças no conceito de renda, surveys de renda bruta ou líquida ou mesmo surveys de gastos, conduzidas em diferentes países e regiões, criam inconsistências que não são facilmente resolvidas.

Com isso uma mesma economia em determinado ano pode oferecer diferentes valores de GINI mensurados em uma mesma survey. O GINI pode ser calculado para a renda bruta (antes do pagamento dos impostos), renda líquida (depois do pagamento dos impostos) ou mesmo para o nível de consumo do indivíduo. Em uma sociedade cujo sistema tributário seja redistributivo, o GINI de renda bruta tende a ser maior do que o GINI de renda líquida. Ademais, devido ao fato de que as classes mais pobres consomem uma fração maior de sua renda, a diferença entre ricos e pobres tende a ser reduzida em surveys de consumo. Uma parte dos ganhos dos ricos tende a ser canalizada para investimentos e poupança e não entra no cálculo.

As medidas de renda nos EUA, por exemplo, são obtidas antes de serem taxadas, enquanto no Reino Unido analisa-se a renda líquida (após impostos e transferências). Desta forma, não é possível verificar se os resultados encontrados na literatura foram obtidos devido à existência efetiva de padrões de causa e efeito da desigualdade econômica ou estes resultados foram fruto apenas das diferenças entre as técnicas e conceitos de mensuração (ATKINSON; BRANDOLINI, 2001).

Um segundo atrito conceitual é a própria abrangência da população coberta pela medida. Isto por que algumas das medidas compiladas pelo WIID são coletadas apenas com a população urbana ou rural, economicamente ativa 
ou com frações geográficas. Por fim, o terceiro e último grande problema que reduz a comparabilidade temporal e internacional dos dados do WIID é a unidade de referência em relação à qual é calculado o índice de GINI, podendo ser um indivíduo ou a família, e calculado em relação ao número de pessoas (per capita) ou ao número de adultos de uma família (per adult). A terceira e última unidade de referência é a unidade de assistência social, utilizada apenas na Escandinávia e na Alemanha.

O próprio manual elaborado pelo UNU-WIDER aponta: "tenha em mente que pontos de dados com definições similares não são definições automaticamente comparáveis, uma vez que diferenças de metodologia de pesquisa nas surveys podem prejudicar a comparabilidade" (UNU/WIDER-UNDP, 2007, p. 15).

Galbraith (2008) e Atkinson e Brandolini (2001) sublinham ainda outro aspecto problemático do DS e UNU-WIDER, que é a falta de validade de face ${ }^{62}$ de algumas mensurações, como, por exemplo, o fato que a Espanha aparece como um país com pequena desigualdade enquanto os países escandinavos (Suécia, Noruega e Dinamarca) encontram-se numa faixa média de desigualdade dentro da OCDE. Outro problema de validade de face é o fato de que o Reino Unido mantém-se como um país de desigualdade média, mesmo existindo uma percepção de um suposto crescimento da desigualdade econômica durante o thatcherismo. Os cinco exemplos apresentam

\footnotetext{
${ }^{62}$ Validade de face é um indicador subjetivo da validade de um indicador. Um exemplo claro de uma medida que viola o princípio da validade de face é um indicador do nível de desenvolvimento econômico que aponte que o Brasil é mais desenvolvido economicamente que os EUA. Obviamente é uma análise bastante imprecisa, uma vez que é possível que de fato a percepção sobre a realidade seja diferente da própria realidade empírica.
} 
situações nas quais os índices de desigualdade apresentados pelo DS e pelo UNU-WIDER vão de encontro às percepções comuns a respeito da distribuição do coeficiente de GINI pelo mundo.

Devido a estes problemas, vamos utilizar em nossa pesquisa o conjunto de dados produzido pelo Projeto Desigualdade da Universidade do Texas (University of Texas Inequality Project - UTIP), um grupo de pesquisa que ao longo das duas últimas décadas tem se dedicado ao desenvolvimento de novas medidas de desigualdade econômica, usando métodos baseados no componente entre grupos do Índice $\mathrm{T}$ de Theil ${ }^{63}$. O UTIP tem como objetivo mensurar a desigualdade por meio de diversas fontes de informação, incluindo dados regionais sobre tributos, emprego e renda, censos sobre a produção manufatureira e banco de dados industriais harmonizados internacionalmente como fonte de informação dos níveis e mudanças da desigualdade econômica.

Este método desenvolvido pela UTIP não requer o uso de micro dados derivados de surveys e, consequentemente, produz como resultado uma infinidade de novas medidas da evolução da desigualdade econômica, comparáveis tanto através do tempo e entre países e que podem ser recuperadas a partir de dados agregados levantados pelos estados e seus respectivos sistemas de contas públicas no passado (GALBRAITH; KUM, 2003 e 2005; GALBRAITH, 2012).

\footnotetext{
${ }^{63}$ A estatística $T$ de Theil é da família de medidas generalizadas de entropia sobre a desigualdade, sendo a única que pode ser exatamente decomposta. Segundo Theil, a diferença entre grupos da estatística $\mathrm{T}$ pode ser pensada como uma medida indireta da informação requerida para transformar probabilidades a priori em posteriores, no qual os pesos populacionais para cada grupo são a priori e a parcela de rendas posteriores (GALBRAITH; KUM, 2003; 2005; GALBRAITH, 2010).
} 
A organização dos dados deriva da constatação de que a distribuição de ganhos é constituída em qualquer economia de um conjunto de entidades institucionais entrelaçadas formada por grupos: firmas, ocupações, indústrias e regiões geográficas $^{64}$. Dado isso, a observação consistente dos movimentos nos ganhos obtidos em relação a estas entidades, tomadas em seus valores médios e comparado entre si, são suficientes para revelar os principais movimentos da distribuição de ganhos como um todo. $\mathrm{E}$ isto seria verdade, na visão do UTIP, mesmo se a cobertura não seja completamente abrangente, contanto que grupos e entidades sejam consistentes ao longo do eixo temporal.

Esses dados semiagregados são, portanto, fontes de informações fundamentais para expandir a capacidade analítica e a abrangência dos bancos de dados sobre desigualdade por dois motivos básicos. Em primeiro lugar, o conceito de desigualdade econômica subjacente a todos os pontos de dado é o mesmo - transversal e temporalmente. Em segundo lugar, é possível reestimar os pontos de dados do passado por meio da mesma técnica se existirem informações sobre esses grupos nas contas nacionais, permitindo o preenchimento de dados faltantes sem a necessidade de interpolação.

Para calcular o Índice $\mathrm{T}$ de Theil é necessário obter duas informações de cada grupo: sua renda total e sua população. De posse destes dados, é possível calcular duas razões fundamentais: a participação de cada grupo na população e a proporção da renda média de cada grupo em relação à renda média da população. O Índice de Theil que identifica o componente entre grupos da desigualdade por meio da somatória

\footnotetext{
64 A única restrição para a escolha das entidades institucionais é que os grupos escolhidos sejam mutuamente exclusivos e coletivamente exaustivos.
} 
do produto destas duas proporções multiplicado pelo logaritmo do segundo termo dos $m$ grupos. A notação formal do índice é:

$$
\boldsymbol{T}=\sum_{i=1}^{m}\left\{\left(\frac{p_{i}}{\boldsymbol{p}}\right) *\left(\frac{y_{i}}{\mu}\right) * \ln \left(\frac{y_{i}}{\mu}\right)\right\}
$$

onde $\boldsymbol{m}$ indica o número de grupos, $\frac{p_{i}}{p}$ é o peso do grupo na população e $\frac{y_{i}}{\mu}$ é a razão entre a renda média $y$ do grupo $i \mathrm{em}$ relação à renda média $\mu$ de toda a populaçãa ${ }^{65}$.

Uma propriedade fundamental do Índice $\mathrm{T}$ de Theilé que a partir de semiagregados harmonizados internacionalmente (mesmos setores em diferentes países e anos) e estáveis ao longo do tempo é possível construir uma série de dados sobre desigualdade a partir da mesma definição consensual. Assim, supera-se o principal defeito do DS e do WIID: a multiplicidade conceitual existente no rol de surveys compiladas como pontos de dado de alta qualidade.

Os dados da Organização das Nações Unidas para o Desenvolvimento Industrial (UNIDO) formam a base dos dados criados pela UTIP sobre a desigualdade de pagamentos no setor industrial, tendo mais de 3200 observações desde 1963. As estatísticas da UNIDO utilizadas pelo UTIP para calcular o Índice $\mathrm{T}$ de Theil sobre desigualdades salariais são duas medidas: o emprego total e o pagamento médio nominal nos setores econômicos desagregados ${ }^{66}$. Os dados da UNIDO são uma

\footnotetext{
65 Devido ao termo logarítmico, o elemento de Theil (o produto de cada um dos grupos) é positivo para os grupos com renda média superior à renda média populacional e negativo caso contrário.

66 A partir de agora denominamos o Índice T de Theil do cálculo da desigualdade de pagamentos no setor industrial como UTIP-UNIDO. Para maiores pormenores sobre os cálculos ver Galbraith e Kum (2003 e 2005).
} 
grande fonte de informação sobre a temática, pois mensuram a distribuição de pagamentos salariais no setor industrial em diferentes categorias econômicas e de maneira harmonizada em todo o planeta, baseando-se na International Standard Industrial Classification (ISIC) organizada pela ONU (Galbraith e Kum, 2003; 2005; Galbraith, 2010).

Basicamente, os dados sobre desigualdade econômica da UTIP combinam informações obtidas a partir do Índice $\mathrm{T}$ de Theil sobre desigualdade de pagamentos no setor industrial do UTIP-UNIDO com as informações oferecidas pelo banco de dados de Deininger e Squire - DS sobre desigualdade econômica mensurada pelo coeficiente de GINI. A UTIP criou, desta forma, uma proxy bastante elaborada da desigualdade econômica com a combinação de informações compilados pelo DS com uma medida mais precisa (embora mais restrita) da dispersão dos pagamentos do setor industrial obtidos no banco de dados da UTIP-UNIDO. Convertem-se, assim, as medidas de desigualdade de pagamento no setor industrial em uma medida da desigualdade de renda bruta domiciliar estimada (EHII - Estimated Household Income Inequality): um banco de dados denso, consistente conceitualmente e possuindo o mesmo formato dos GINIs compilados pelo DS e UNU-WIDER.

Assumindo que todos os erros de mensuração, exceto os causados pelo tipo de survey utilizada na coleta de dados, são aleatórios, Galbraith e Kum (2003) utilizaram um modelo de Mínimos Quadrados Ordinários (MQO) apresentado na equação (3.2) para estimar a desigualdade econômica. Nesta equação o GINI-DS representa a medida do coeficiente de GINI coletada por Deininger e Square (1996), a é uma constante, UTIP-UNIDO é o índice de Theil baseado na 
medida da desigualdade de pagamentos no setor industrial e $\mathbf{X}$ é um vetor de condicionantes. Nesse vetor $\mathbf{X}$ são incluídas um conjunto de dummies refletindo as fontes de dados ${ }^{67}$ e outras informações relevantes como a razão entre emprego industrial relacionada com a população total, o grau de urbanização e o crescimento populacional.

$$
\operatorname{Ln}(\text { GIN }- \text { DS })=\alpha+\beta * \operatorname{Ln}(\text { UTIP }- \text { UNIDO })+\lambda * X+\varepsilon
$$

Em seguida, o indicador de desigualdade principal, EHII, é definido, na forma logarítmica, como:

$$
\operatorname{Ln}(\text { EHII })=\widehat{\alpha}+\widehat{\boldsymbol{\beta}} * \operatorname{Ln}(\mathrm{UTIP}-\mathrm{UNIDO})+\hat{\lambda} * X_{i}{ }^{68}
$$

onde EHII significa a Desigualdade de Renda Bruta Domiciliar Estimada, UTIP-UNIDO é o índice de desigualdade salarial, da UTIP-UNIDO e $\mathbf{X}$ é a matriz de variáveis condicionantes. E os coeficientes estimados são termos determinísticos extraídos da equação (3.2). Esta abordagem permite uma forma apropriada de extrapolação teórica e empiricamente orientada por meio da replicação dos dados da UTIP-UNIDO com as medidas estimadas de EHII (GIMET; LAGOARDE-SEGOT, 2011) ${ }^{69}$.

\footnotetext{
${ }^{67}$ As variáveis dummies indicadoras do tipo de survey utilizado na compilação de dados do DS são três: indicador de renda bruta ou líquida, indicador de renda domiciliar ou individual, e indicador de renda ou consumo.

${ }^{68}$ Como a distribuição do Índice T de Theil da UTIP-UNIDO e do GINI da UNU - WIDER possuem uma distribuição log-normal, para aumentar a eficiência do modelo de regressão, as duas medidas de desigualdade estão em formato logarítmico. Assim o coeficiente é uma estimativa da elasticidade na relação entre desigualdade de pagamentos no setor industrial e desigualdade econômica.

69 A análise da estimação em seus pormenores e os resultados podem ser vistos em Galbraith (2012, p. 81-97).
} 
Nas palavras de um dos líderes do projeto UTIP:

Essas medidas são amplamente consistentes com as medidas convencionais de desigualdade de renda obtidas por meio de survey ou podem ser feitas por meio de ajuste estatístico, permitindo diferenças conceituais entre salário e renda e para os diferentes tipos de desigualdade que são relatados nas pesquisas baseadas em survey (ex: renda, despesas, bruta ou líquida, domiciliar ou pessoal). (GALBRAITH, 2010).

A vantagem é que a cobertura em termos de países e anos é muito maior e a uniformidade de método produz coeficientes que são comparáveis tanto através do tempo e quanto no espaço. O método UTIP, assim, permite a formação de conjuntos de dados em painel quase balanceados com mais de três mil observações anos-país, abrangendo mais de 160 países ao longo de três ou quatro décadas. (GALBRAITH, 2008).

Os dados da Desigualdade de Renda Bruta Domiciliar Estimada (EHII) foram amplamente utilizados na literatura sobre desigualdade. Herzer e Nunnenkamp (2011) usaram-no para analisar a relação entre desigualdade e a saúde da população. Herzer e Vollmer (2012) afirmaram que a grande vantagem do EHII é que os dados são totalmente comparáveis no espaço e no tempo e usaram-no para estimar o efeito de longo prazo da desigualdade de renda sobre a renda per capita de 46 países durante o período 1970-1995. Gimet e Lagoarde-Segot (2011), por sua vez, usaram os dados do EHII para analisar o impacto das diferentes características do setor financeiro na distribuição de renda dos países. Eles também afirmaram que o UTIP-EHII é a mais precisa e extensiva fonte de informação sobre a distribuição de renda já elaborada. Finalmente, Meschi 
e Vivarelli (2009) utilizaram os dados de EHII para estimar o impacto do comércio na desigualdade de renda em uma amostra de 65 países em desenvolvimento, destacando a comparabilidade dos dados através do tempo e entre países.

\subsubsection{Medidas alternativas de desigualdade econômica}

Do mesmo modo que existe um vigoroso debate sobre como o fenômeno da democracia deve ser mensurado empiricamente, a literatura também diverge sobre quais são as melhores formas de medir a desigualdade econômica. O problema sobre esse conceito é ainda mais fundamental, pois a captura de uma medida fina sobre a distribuição de renda dentro de uma determinada sociedade requer grandes investimentos de recursos para a obtenção de um único ponto de dado, tal como surveys de consumo e renda.

Deste modo, nessa seção iremos introduzir outras três medidas de desigualdade econômica. Duas adotam diferentes estratégias empíricas para produzir mais dados que mensuram o mesmo conceito tratado pelo UTIP-EHII: o coeficiente de GINI. A primeira é o Standardized Income Inequality Data (SIID) de Salvatore J. Babones e María José Alvarez-Rivadulla (2007) e a segunda é o Standardized World Income Inequality Database (SWIID) de Frederick Solt (2009). A terceira, Capital Shares, captura o quanto dos recursos de um determinado país são controlados pelos detentores do capital e foi elaborada por Daniel Ortega e Francisco Rodríguez (2006). As três medidas são abrangentes temporal e transversalmente.

Temos como expectativa encontrar relações semelhantes para diferentes mensurações do GINI, uma vez que o conceito objeto da análise é a curva de Lorenz do coeficiente de 
GINI e a fonte primária dos dados de desigualdades elaborados pela UTIP, pelo SWIID e pelo SIID são a mesma: a compilação feita pelo UNU-WIDER. Por sua vez, em relação à terceira medida, que foi utilizada por Houle (2009) para analisar a relação entre desigualdade e processos de democratização, as expectativas são mais incertas, uma vez que a variável captura outro aspecto da desigualdade: a divisão de recursos entre os detentores do capital e o resto da sociedade e não apenas a desigualdade no fluxo de renda e nem efeitos que acontecem ao longo de toda a distribuição de renda. Uma característica comum de todas as 4 medidas e que justifica a escolha empírica é a extensão da cobertura dos dados, abrangendo tantos países desenvolvidos quanto em desenvolvimento, em todos os continentes e por um extenso período de tempo.

3.2.1.1 Standardized Income Inequality Data (SIID) e Standardized World Income Inequality Data (SWIID)

As medidas de desigualdade econômica elaboradas pelo SIID e pelo SWIID são tentativas de melhorar a consistência e comparabilidade internacional e temporal dos dados sobre desigualdade econômica compilados pela UNU-WIDER por técnicas diferentes das utilizadas no UTIP-EHII. Os trabalhos de Babones e Alvarez-Rivadulla (2007) e de Solt (2009) tem um mesmo objetivo: padronizar os dados do WIID em uma nova variável que reduza os atritos conceituais entre os diferentes pontos de GINIs estimados. Deste modo, assim como o exercício empírico realizado pelo projeto UTIP-EHII, o SIID e o SWIID re-estimam os coeficientes de GINI do WIID para maximizar a comparabilidade dos dados, mantendo a maior cobertura possível em termos geográficos e temporais. 
O SIID versão 2 possui 1218 pontos de dados estimados de GINI para 143 países entre 1960 e 1999 para a desigualdade em renda per capita bruta da família utilizando do arcabouço regressional de MQO para padronizar os dados do WIID após classificar conceitualmente os diferentes pontos em categorias distintas de conceitos de renda e unidades de referência (BABONES; ALVAREZ-RIVADULLA, 2007). Babones (2008) realiza uma interpolação polinomial para preencher os valores faltantes. O resultado final da interpolação, SIID versão 3, resulta em séries temporais contínuas para 134 países entre 1955 e 2005. Além do mais, esta última versão possui um indicador para informar se os dados são estimados para além ou dentro da amostra do WIID. Para os dados de fora da amostra, são repetidos os primeiros e últimos valores encontrados. Em nosso banco de dados 2302 observações do SIID versão 3 não extrapolados para fora da amostra foram imputadas ${ }^{70}$. Nas análises utilizaremos os dados do SIID versão 3 não extrapolados para fora da amostra ${ }^{71}$.

Por sua vez, o SWIID utiliza-se de um algoritmo mais sofisticado para padronizar os dados do UNU-WIID (versão 2.0c), utilizando como parâmetros os dados de duas séries de desigualdade de renda elaboradas pelo Luxembourg Income Study (LIS) ${ }^{72}$, desigualdade bruta e desigualdade líquida, e

\footnotetext{
${ }^{70}$ Não pudemos inserir todos os dados do SIID, pois alguns pontos de dados desse banco não são países independentes como, por exemplo, Hong Kong e Porto Rico.

71 Agradecemos a gentileza dos professores Salvatore Babones e María Alvarez-Rivadulla por terem nos fornecido os dados das versões 2 e 3 de SIID.

72 O LIS possui o maior banco de dados comparável sobre desigualdade ao utilizar a mesma metodologia de survey em diferentes países e anos, mas a sua cobertura temporal e internacional é bastante limitada. Seus dados cobrem os 30 países mais ricos do mundo e seus dados estão disponíveis apenas a partir de 1993.
} 
regressões não paramétricas para a interpolação e padronização dos dados da UNU-WIDER. O primeiro passo da padronização do SWIID foi eliminar as observações que não cobrem toda a população de um país, tal como feito por Babones e Alvarez-Rivadulla (2007) na elaboração do SIID e incluir as variáveis de desigualdade de renda líquida e bruta do LIS, que são para Solt (2009) os dados melhor comparáveis sobre desigualdade e servem, portanto, de baseline para o algoritmo de padronização dos dados.

Em seguida, os dados foram organizados de acordo com 21 categorias empíricas decorrentes de combinações das cinco unidades básicas de referência e dos quatro conceitos de renda existentes no $\mathrm{WIID}^{73}$, mais as duas categorias básicas do LIS: rendas líquidas e brutas familiares adulto-equivalentes, consideradas como grupos distintos ${ }^{74}$. Assim foi formado um novo banco de dados com a unidade básica de análise sendo o país/ ano/categoria de renda e unidade referência. A partir destes dados foi calculada para cada país/ano a razão entre as categorias, o que permite a extrapolação dos dados para os anos nos quais algumas das categorias estão ausentes.

Um suposto assumido é que estas razões são estáveis no médio prazo, sendo possível usar a razão encontrada em um ano mais próximo para estimar o dado faltante. Com isso em mente, para os países com dados suficientes foram realizadas regressões não paramétricas (LOESS), incorporando o máximo

\footnotetext{
${ }^{73}$ Unidades de referência no WIID: familiar per capita; familiar adulto equivalente; familiar; por empregado; e per capita. Conceitos de renda no WIID: renda líquida; renda bruta; consumo; e não identificada.

${ }^{74}$ A escala família equivalente é o resultado obtido pela ponderação do rendimento de cada família pela sua dimensão em número de indivíduos. A escala de equivalência do LIS baseia-se na ponderação da renda familiar pela raiz quadrada do número de membros da família.
} 
de informação disponível por meio de curvas de suavização ponto por ponto. Em seguida, modelos multiníveis foram aplicados para estimar as razões de países com menos informações, incluindo no modelo indicadores de década-país, década-região, país, região e se o país é desenvolvido ou em desenvolvimento. As predições foram combinadas para estimar a razão entre as categorias para diversos países, tendo como baseline de comparação a renda líquida e depois a bruta do LIS.

O terceiro passo da padronização dos dados do SWIID foi feito baseado no suposto que a mudança na distribuição de renda de determinado país é lenta ao longo do tempo. Como a desigualdade contemporânea deve ser similar à desigualdade nos anos precedentes, foi usado um algoritmo que computa uma média móvel ponderada em 5 anos exposta na equação (3.4). As únicas exceções para as quais não foram aplicadas o algoritmo de suavização foram as mudanças dramáticas ocorridas no LIS, que são consistentes ao longo dos eixos temporais e transversais, e as mudanças ocorridas nos países comunistas após o colapso da URSS entre os anos de 1989 e 1992.

$$
\operatorname{SWIDav}_{i t}=\left(\frac{\mathbf{1}}{\mathbf{6}}\right) *\left(\operatorname{SWIID}_{i t-2}+\operatorname{SWIID}_{i t-1}+2\left(\operatorname{SWIID}_{i t}\right)+\operatorname{SWII}_{i t+1}+\operatorname{SWIID}_{i t+2}\right) \text { (Eq. 3.4) }
$$

Finalmente, o quarto e último passo foi a re-estimação dos dados em 100 vezes por meio da aplicação de uma simulação de Monte Carlo e do algoritmo da média móvel em cada simulação. Os valores para todos os dados faltantes depois de 1975 foram interpolados em cada estimação. Como resultado foram gerados duas novas séries de dados padronizados em desigualdade de renda bruta adulto equivalente da família e renda líquida adulto equivalente da família para mais de 4000 pontos de dados e cobrindo 153 países. 
A variável Capital Shares foi compilada por Ortega e Rodriguez (2006), baseando-se nos dados da UNIDO, que desde 1963 coleta informações sobre os agregados industriais para 181 países. Os dados da UNIDO, os mesmos utilizados nas criações do UTIP-UNIDO e no EHII, são coletados por meio de questionários enviados aos governos nacionais. Após o recebimento das informações, os dados são conferidos visando à correção de inconsistências e erros e posteriormente são suplementados com outras fontes nacionais e internacionais de informações econômicas. A verificação é feita visando garantir a comparabilidade internacional e temporal dos dados. Os dados da UNIDO incluem medidas dos valores adicionados agregados e salários para 136 países permitindo o cálculo do capital share, definido como ${ }^{75}$ :

$$
\text { Capshare }=1-\left(\frac{\text { salarios }}{\text { valor adicional agregado }}\right)
$$

De acordo com Houle (2009), o conceito de Capital Shares é bastante usado na literatura em política comparada para mensurar a desigualdade ${ }^{76}$ por possuir vantagens teóricas e empíricas: a) são consistentes com a literatura que foca o problema da desigualdade entre grupos da sociedade e não a desigualdade total; b) a capital shares observa, sobretudo, a

\footnotetext{
75 Salários são todos os pagamentos feitos aos empregados em um ano e valor adicional é o resultado dos valores dos outputs menos os valores dos inputs (materiais e insumos para a produção e custos de serviços industriais). Agradecemos a gentileza do professor Christian Houle por ter nos fornecido os dados de capital share.

76 Os autores citados são Dunning (2008), Acemoglu e Robinson (2006) e Przeworski e outros (2000)
} 
desigualdade entre pobres e a elite, ao medir a renda relativa das elites; c) a variável é coletada por uma única fonte - a UNIDO - cuja metodologia é semelhante para todos os países.

Por outro lado, os próprios autores dos dados verificaram empiricamente que esta variável é forte e negativamente relacionada com o nível de desenvolvimento. Ortega e Rodriguez (2006) estimaram que as economias mais desenvolvidas possuem em média 10 pontos percentuais a menos de capital shares do que as economias de renda média e 20 pontos percentuais a menos do que países de baixa renda. Tal relação é robusta a diferentes especificações ${ }^{77}$. O mesmo argumento é feito por Ansell e Samuels (2014), que entendem que a variável utilizada por Houle (2009) é mais uma proxy de desenvolvimento do que uma medida de desigualdade, o que explicaria o fato que os achados de Houle sobre a relação entre desigualdade e democratização serem muito semelhantes aos achados de Przeworski e outros (2000) sobre a relação entre desenvolvimento e democratização.

Ademais, um segundo ponto problematizado por Ansell e Samuels (2014) decorre do fato de que a fatia pertencente ao capital em uma dada sociedade pode ser mais ou menos equitativamente distribuída. Isto é, a fração pertencente ao capital em dada economia não nos informa muito sobre como o capital é distribuído entre os agentes econômicos. Caso a fração do produto adicional pertencendo ao capital seja elevada, mas a propriedade do capital ser equitativamente distribuída, a variável não mensuraria adequadamente a desigualdade econômica.

77 Em nossos dados, a correlação entre Capital Shares e o log de renda per capita é de cerca de -0.4 . 
Piketty (2014), inclusive, mostra que o período pós-Segunda Guerra Mundial é justamente aquele no qual a propriedade do capital ocupou um peso menor em relação à renda nacional nas economias mais desenvolvidas da América do Norte, Europa Ocidental e Japão. E também demonstra claramente que a $2^{\text {a }}$ metade do século XX é justamente o período do surgimento de uma classe média patrimonial: uma classe média detentora de capital e que retira sua renda mensal não apenas da renda do trabalho, mas também de renda deste capital.

\subsubsection{Dados de desigualdade econômica}

Em nossa pesquisa iremos utilizar como fonte de dados principal o banco da desigualdade de renda bruta domiciliar estimada (EHII) elaborado pelo Projeto Desigualdade da Universidade do Texas (UTIP). Nessa seção apresentamos algumas estatísticas descritivas de EHII e no capítulo 4 analisaremos os efeitos heterogêneos da democracia sobre a desigualdade. O banco de dados original inclui 3686 pontos de dados de EHII para 145 países entre 1963 e $2008^{78}$. Com projeções lineares sempre que havia de um a no máximo oito anos faltantes entre dois pontos de EHII, o banco cresceu para 4138 pontos.

Optamos por priorizar a análise do EHII por dois motivos. É a única proposta metodológica de obtenção de dados que permite a recuperação de pontos do passado, enquanto as metodologias propostas por Solt (2009) - Standardized World Income Inequality Data (SWIID) e Babones e Alvarez-

\footnotetext{
${ }^{78}$ Quando um país foi dividido ou unificado, a parcela principal do território permaneceu sendo o mesmo país e as outras parcelas tornaram-se novos. Foram divididos Paquistão (Paquistão e Bangladesh) e Etiópia (Etiópia e Eritréia). O país unificado foi a Alemanha. Após a divisão da Tchecoslováquia dois novos países foram criados: República Tcheca e Eslováquia, o mesmo foi feito para a divisão da Iugoslávia.
} 
-Rivadulla (2007) - Standardized Income Inequality Data (SIID) são aplicáveis apenas nos casos onde existem dados de survey de renda. $\mathrm{O}$ segundo ponto é que a última versão do UTIP-EHII foi publicada em dezembro de 2013, sendo o mais atual dos bancos de dados sobre desigualdade. Por outro lado, como o SWIID possui uma cobertura tão extensa quanto o do UTIP-EHII e também cobre um vasto período de tempo, 1960 a 2008, também apresentaremos as estatísticas básicas dessa variável $^{79}$. Contando com as interpolações realizadas, temos 4710 pontos de dados no SWIID, sendo que deste total 1967 são ditaduras e 2463 são democracias.

As principais estatísticas descritivas de EHII são apresentadas na Tabela 3 e sua densidade de kernel no Gráfico 3 . Em ambas as figuras apresentamos as informações para todo a amostra e também para cada tipo de regime político. Estendemos em todas as análises os valores de GINI e de Capital Shares para um intervalo entre 0 e 100 e não limitado entre 0 e 1 . O motivo para tal escolha decorre do fato que um GINI e Capital Shares que variam de 0 a 100 facilitam a interpretação dos coeficientes das regressões quantílica e lineares do próximo capítulo.

No Gráfico 3 apresentamos a distribuição da variável dependente por meio da densidade de kernel. No eixo horizontal está o escopo de valores encontrados na variável dependente e no eixo vertical a concentração de dados em cada intervalo de pontos. A linha sólida indica a distribuição de toda a amostra. Os menores valores são próximos de um GINI de 20 e os maiores de um GINI de 60, mas os dados estão concentrados entre os GINIs de valores de 30 a 50 e a distribuição apresenta uma

\footnotetext{
79 Ambos os trabalhos são amplamente citados na literatura: Solt (2009) tem mais de 351 citações no Google Scholar, enquanto o trabalho do UTIP-EHII tem cerca de 190 citações. Por sua vez, o banco de dados de Babones e Alvarez-Rivadulla (2007) - Standardized Income Inequality Data (SIID) - também é frequentemente citado, tendo cerca de 180 citações. Dados vistos em: 25 maio 2014.
} 
forma bimodal. O mesmo formato bimodal é encontrado quando vemos a distribuição de EHII apenas para as democracias (linha pontilhada). Ainda que os dados variem entre os valores de 20 e 60, os dois vértices da distribuição estão entre 30 e 40 e entre 40 e 50, sendo o primeiro vértice mais elevado. Já a distribuição de desigualdade econômica em ditaduras (linha tracejada) tem um formato unimodal e o vértice está localizado próximo do GINI de 50. Mas assim como as outras, a distribuição varia entre os GINIs de 20 e 60.

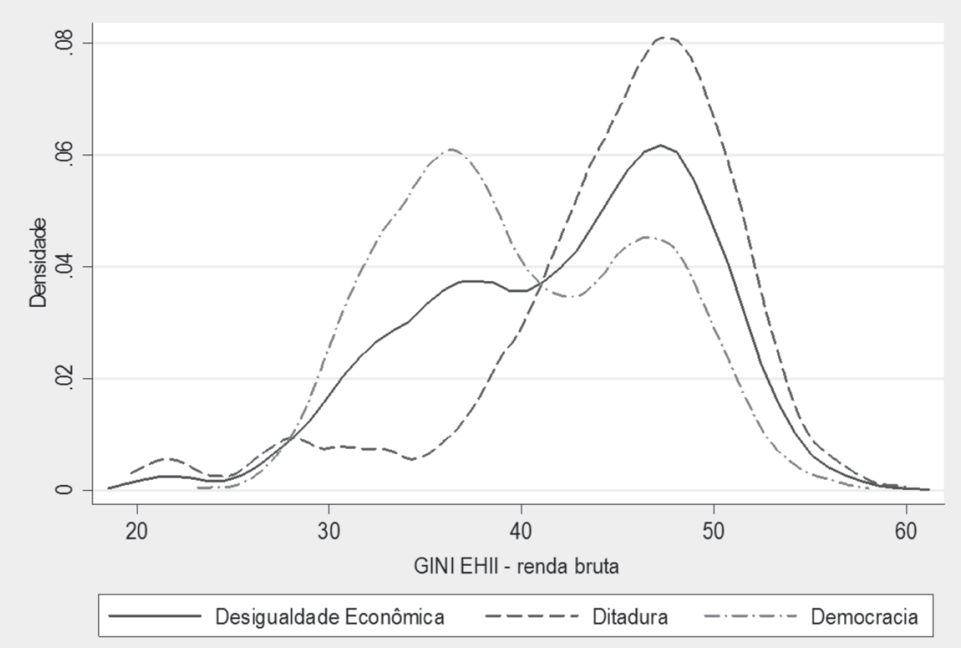

Gráfico 3 - Densidades de Kernel de desigualdade econômica bruta (EHII) por regimes políticos Fonte: UTIP - EHII e CGV

Ademais, fica claro no Gráfico 3 que o pico da distribuição de desigualdade econômica em democracias é menor que o pico da distribuição em ditaduras, indicado pela diferença na curtose das duas dimensões, embora ambas sejam menos achatadas que a distribuição normal. Os dados descritivos da Tabela 
3 mostram ainda que a média e a mediana de desigualdade nas democracias são menores do que nas ditaduras. A proximidade entre os valores médios e medianos de cada curva demonstram que as três distribuições de GINI aproximam-se de uma normal. Por outro lado, curiosamente, mesmo tendo uma média superior à democracia, os primeiros 39 pontos de dados mínimos são todos ditatoriais e referem-se à Alemanha Oriental e Tchecoslováquia. Por sua vez, os desvios padrões e os valores máximos das duas distribuições são semelhantes. Finalmente, as simetrias das curvas são discrepantes, indicando que as duas distribuições estão inclinadas para lados diferentes da média ${ }^{80}$.

Tabela 3 - Dados descritivos de EHII_renda bruta

\begin{tabular}{lccc}
\hline & Toda amostra & Democracias & Ditaduras \\
\hline Média & 42.26 & 39.98 & 44.72 \\
Desvio Padrão & 7.11 & 6.51 & 6.90 \\
Mediana & 43.45 & 39.01 & 46.17 \\
Assimetria & -0.46 & 0.18 & -1.34 \\
Curtose & 2.60 & 2.05 & 5.03 \\
Mínimo & 19.70 & 23.18 & 19.70 \\
Máximo & 59.96 & 58.03 & 59.96 \\
Número de Observações & 4138 & 2145 & 1993 \\
\hline
\end{tabular}

Observação 1: 4 países - anos ditatoriais são mais desiguais que todos os países-anos democráticos: Angola - 1993; Camboja - 1995; Kuwait - 1991 e 1992.

Observação 2: 39 países - anos ditatoriais são mais iguais que todos os países-anos democráticos: Tchecoslováquia - 1963 a 1986 e Alemanha Oriental - 1975 a 1989.

Fonte: UTIP - EHII e CGV

\footnotetext{
${ }^{80}$ Assimetria ou skewness é a medida do grau em que uma distribuição de probabilidade está inclinada para um lado da média. Uma assimetria negativa indica que a cauda no lado esquerdo da função densidade é maior ou mais ampla do que a do lado direito. Já a curtose é uma medida de dispersão que caracteriza o pico ou "achatamento" da curva. Uma curtose de 0 indica o mesmo achatamento da distribuição normal.
} 
Os achados são um pouco distintos quando observamos os dados de desigualdade econômica bruta pelo SWIID. Os dados estão disponíveis na Tabela 4 e sua densidade de kernel no Gráfico 4. Assim como no gráfico anterior, em ambas as figuras apresentamos as informações para toda a amostra e também divididas de acordo com o regime político. O que fica evidente ao analisamos as distribuições de kernel do Gráfico 4 são que as distribuições de toda a amostra ou dividida por regimes políticos são muito mais semelhantes em praticamente todos os aspectos, variando apenas na curtose de cada curva. Em todas as três distribuições (que seguem o mesmo padrão de formas do Gráfico 3) as curvas são unimodais com o centro da distribuição posicionado de maneira semelhante, os dados variam de GINIs inferiores à 20 à GINIs superiores à 80 , embora boa parte da concentração esteja entre os GINIs de 30 e 50.

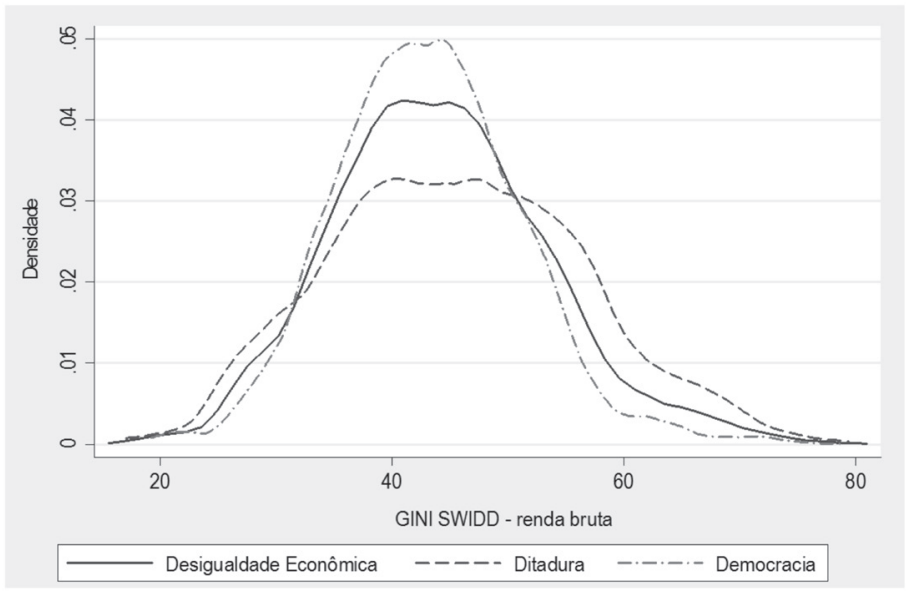

Gráfico 4 - Densidades de Kernel de desigualdade econômica bruta (SWIID) por regimes políticos Fonte: UTIP - EHII e CGV

Já na Tabela 4 as estatísticas descritivas das três distribuições são essencialmente semelhantes. As médias e medianas 
são muito próximas, distando menos de 3 pontos de GINI e os desvios padrões também. O sinal da assimetria também é igual, indicando uma inclinação em relação à média semelhante. A curtose das ditaduras é um pouco menor, o que reflete o fato que o vértice desta distribuição ser mais achatado que os vértices das outras duas curvas, mas as três são mais alongadas que uma distribuição normal. Os mínimos e máximos também convergem.

Em relação aos dados do EHII, as médias e medianas do SWIIDs, com exceção apenas da mediana das ditaduras, são maiores. Por outro lado, as diferenças absolutas entre EHII e SWIID para renda bruta das ditaduras são bem menores $(0.85$ ponto de média e 0.76 de mediana) do que as diferenças absolutas das democracias ( 3.15 pontos de média e 3.9 de mediana). Os desvios padrões de cada uma das curvas também são maiores no SWIID, assim como a amplitude total entre os valores mínimos e máximos em média 22.9 pontos de GINI maior nas três curvas de SWIID.

Tabela 4 - Dados descritivos de SWIID_renda bruta

\begin{tabular}{lccc}
\hline & Toda amostra & Democracias & Ditaduras \\
\hline Média & 44.15 & 43.14 & 45.57 \\
Desvio Padrão & 9.32 & 7.99 & 10.90 \\
Mediana & 43.65 & 42.91 & 45.41 \\
Assimetria & 0.34 & 0.33 & 0.16 \\
Curtose & 3.27 & 3.68 & 2.65 \\
Mínimo & 17.10 & 19.25 & 17.10 \\
Máximo & 79.39 & 78.65 & 79.39 \\
Número de Observações & 4710 & 2463 & 1967 \\
\hline
\end{tabular}

Observação 1: 1 país-ano ditatorial é mais desiguais que todos os países-anos democráticos: Maldivas - 1998.

Observação 2: 9 países-anos ditatoriais são mais iguais que todos os países-anos democráticos: Bulgária - 1967 a 1974 e Romênia - 1989.

Fonte: SWIID e CGV 
Tabela 5 - Estatística descritiva dos dados de desigualdade

\begin{tabular}{|c|c|c|c|c|c|}
\hline \multicolumn{6}{|c|}{1 - Correlações entre as Medidas de Desigualdade } \\
\hline & EHII & $\begin{array}{l}\text { SIID_ } \\
\text { bruto }\end{array}$ & $\begin{array}{l}\text { SWIID_ } \\
\text { líquido }\end{array}$ & $\begin{array}{c}\text { SWIID_ } \\
\text { bruto }\end{array}$ & \\
\hline \multicolumn{6}{|l|}{ EHII } \\
\hline SIID_bruto & 0.62 & & & & \\
\hline SWIID_liquido & 0.71 & 0.73 & & & \\
\hline SWIID_bruto & 0.53 & 0.73 & 0.86 & & \\
\hline Capshare & 0.47 & 0.26 & 0.41 & 0.25 & \\
\hline \multicolumn{6}{|c|}{2 - Dados Descritivos } \\
\hline & $\mathbf{N}$ & $\begin{array}{l}\text { Média } \\
\text { Geral }\end{array}$ & $\begin{array}{l}\text { Desvio } \\
\text { Padrão }\end{array}$ & $\begin{array}{c}\text { Média } \\
\text { Democracias }\end{array}$ & $\begin{array}{c}\text { Média } \\
\text { Ditaduras }\end{array}$ \\
\hline EHII & 4138 & 42.26 & 7.11 & 39.98 & 44.72 \\
\hline SIID_bruto & 2302 & 42.54 & 9.16 & 42.22 & 42.88 \\
\hline SWIID_liquido & 4710 & 39.05 & 11.14 & 36.54 & 42.55 \\
\hline SWIID_bruto & 4710 & 44.15 & 9.32 & 43.14 & 45.57 \\
\hline Capshare & 3427 & 64.21 & 12.66 & 60.86 & 67.40 \\
\hline
\end{tabular}

Fonte: UTIP-EHII, SIID, SWIID, CAPSHARE e CGV

Na Tabela 5 apresentamos a descrição de todas as outras variáveis de desigualdade, incluindo a mensuração de SWIID para renda líquida, e mostramos como estão fortemente relacionadas com a variável EHII. Como podemos ver nesta tabela, as quatro diferentes mensurações do GINI são bastante correlacionadas, ainda que a relação menor seja justamente entre o SWIID_bruto (GINI para renda bruta) e o EHII. Por outro lado, é interessante observar que a medida do SIID que mensura um índice de GINI para renda bruta tem a mesma correlação com as duas diferentes medidas do SWIID, enquanto o coeficiente de GINI do EHII é mais correlacionado com SWIID_líquido (GINI para renda líquida) do que com o 
SWIID_bruto, embora na definição apresentada pela UTIP a medida seja sobre a renda bruta.

Além das variáveis sobre GINI, também introduzimos na Tabela 5 a variável sobre o quanto dos recursos de um determinado país são controlados pelos detentores do capital. A diferença entre a correlação das variáveis é visível. As correlações da variável Capital_Share [capshare] com os índices de SWIID_líquido e EHII estão na casa do 0.4 enquanto a correlação com os índices de renda bruta do SWIID_bruto e do SIID_ bruto estão próximas de 0.25 . Além do mais, a própria média e desvio padrão da variável de Capital_Share é superior aos das outras quatro variáveis de GINI, o que é esperado, uma vez que o conceito mensurado é essencialmente distinto, enquanto as outras possuem estratégias metodológicas diferentes para a computação dos dados, mas tomam como base o mesmo conceito do coeficiente de GINI e o mesmo dado original do WIID.

Observando os dados descritivos da Tabela 5 - que também estão divididos entre ditaduras e democracias, vemos claramente que para todas as variáveis as médias de desigualdade em democracias são menores do que as médias em ditaduras. $\mathrm{E}$ as únicas variáveis que tem uma diferença ínfima entre as médias de democracias e ditaduras são os dados de desigualdade bruta do SIID e do SWIID. A diferença entre a desigualdade bruta mensurada pelo EHII é de cerca de 4.5 pontos na escala do GINI, enquanto a diferença entre a desigualdade líquida mensurada pelo SWIID é de 6 pontos. Já em relação ao papel do capital no valor agregado da economia, em ditaduras o capital ocupa uma parcela de $67.4 \%$ enquanto em democracias esse valor cai para $60.9 \%$. 


\subsection{Relação descritiva entre desigualdade e democracia}

Nesta seção apresentamos alguns dados descritivos sobre e relação entre as duas principais variáveis da pesquisa. Para regimes políticos usamos os dados de Cheibub, Gandhi e Vreeland (2010). Sublinhamos, mais uma vez, que assumimos a mensuração dicotômica defendida pelo CGV, que define democracia como um regime no qual existe competição política regulada por eleições. Dividimos nossa amostra em dois grupos distintos de países. O primeiro grupo consiste dos países que não fizeram nenhuma transição política ao longo do período entre 1960 e 2008. O segundo grupo é formado pelos países que fizeram transições democráticas e/ou autoritárias. Obviamente não podemos afirmar que os regimes que não transitaram sejam mais estáveis, uma vez que é possível que tenha havido mudanças de sistema político e de governo sem que a característica democrática ou não democrática do regime tenha sido alterada.

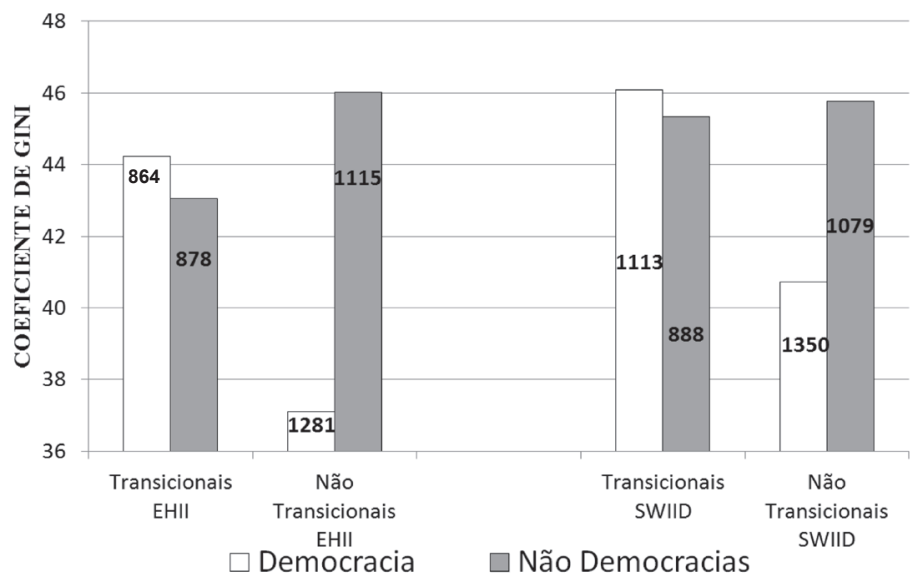

Gráfico 5 - Médias de Desigualdade GINI (EHII_bruto e SWIID_bruto) Fonte: CGV, UTIP-EHII, SWIID 
Optamos por apresentar os dados de acordo com essa divisão, pois há uma importante consequência metodológica da existência de inúmeros casos de países que não atravessam alguma transição política entre a década de 1960 e a primeira década do século XXI: a inadequação do uso de efeitos fixos na estimação em painel. Caso optássemos pelo uso de efeitos fixos na análise empírica, todos estes casos que não apresentam transições (ou variação na variável independente) seriam eliminados da análise: cerca de $48 \%$ dos dados do EHII e 44\% dos dados do SWIID.

O Gráfico 5 mostra a média de desigualdade em cada um desses dois grupos, tanto no GINI de EHII quanto no GINI do SWIID, sempre dividindo os países-anos em democráticos e não democráticos. No eixo vertical está exposto o valor médio do GINI para cada um dos grupos. No primeiro conjunto de barras temos os dados de EHII e no segundo os de SWIID. Em negrito - no corpo de cada barra - está exposto o número de países-anos de cada grupo. O menor número de países-anos em ambos os conjuntos são das não democracias transicionais (países-anos ditatoriais em países que fizeram alguma transição política), respectivamente 878 (em EHII) e 888 (em SWIID) países-anos; e também das democracias transicionais de EHII: 864 países-anos. Todos os outros grupos possuem mais de 1000 países-anos.

Outra importante constatação que é possível obter a partir da análise das barras do Gráfico 5 é que embora em todas as amostras expostas na Tabela 5 as democracias apresentaram média do GINI inferior ao GINI das ditaduras, podemos ver que isso está nitidamente associado a grande diferença que existe entre os GINIs das ditaduras não transicionais em relação às democracias não transicionais, diferença que se 
sobressai ainda mais ao analisarmos os dados de EHII. A diferença no SWIID é de 5 pontos de GINI enquanto a diferença no EHII é de 8.9 pontos. Mas caso optemos por analisar apenas os dados de países que passaram por alguma transição política, as democracias são ligeiramente mais desiguais do que as ditaduras: uma diferença de 1.17 pontos do GINI em EHII e de 0.75 em SWIID. Desta forma, fica evidente que a adoção de uma especificação de um modelo com efeitos fixos gerará um viés importante na análise para encontrar um efeito positivo do ponto de vista estatístico - da democracia sobre a desigualdade (democracia aumentando desigualdade).

Por outro lado, é importante salientar que as comparações realizadas até aqui ainda são preliminares, não sendo possível elaborar nenhuma inferência causal a partir destes dados. Além de questões metodológicas relacionadas à existência de um potencial problema de causalidade reversa na relação entre democracia e desigualdade, existem inúmeros outros fatores de confusão que afetam esta relação e que precisam ser levados em conta antes de inferirmos a partir de dados observacionais.

\section{$\not 8$}

Avançando na análise da relação entre as duas variáveis nos Gráficos 6 e 7 (p. 148 e 150), apresentamos a evolução no tempo da média da desigualdade econômica em cada um dos grupos do Gráfico 5 e também para toda a amostra. Observamos a trajetória dos 4 diferentes tipos de regimes - democracias versus ditaduras e a natureza transicional ou não do regime - ao longo do período abrangido pela década de 1970 até à primeira década do século XXI. Visando remediar o problema de dados faltantes, observamos as médias temporais em intervalos 
de cinco anos, começando no ano de 1970 até o período quadrienal entre 2005 e 2008. Um ponto importante a ser considerado na análise dos gráficos 6 e 7 é que as tendências dos regimes que tiveram transição são afetadas pela direção da transição política, dificultando a interpretação das movimentações e da evolução no tempo de suas curvas. Já para os dados de regimes que permaneceram iguais, as tendências indicam de fato qual foi a evolução da desigualdade durante estes 38 anos analisados.

No Gráfico 6 apresentamos os dados de desigualdade econômica mensurados pelo EHII. Neste gráfico temos 5 curvas distintas. No eixo horizontal estão dispostos os quinquênios que dividem o período entre 1970 e 2008, no eixo vertical estão os valores médios de GINI para cada um dos grupos. As quatro primeiras curvas referem-se às democracias e ditaduras transicionais ou não e a quinta à evolução da desigualdade em toda a amostra. A curva escura e sem marcador indica que ao longo do período houve um crescimento pequeno da média de desigualdade entre os países em todo o mundo.

O crescimento da média de desigualdade ocorrido nas democracias não transicionais é uma tendência maior e mais estável que nas outras curvas. O que, por sua vez, corrobora a literatura sobre a expansão da desigualdade na América do Norte e Europa. Boa parte da discussão é centrada no debate dos efeitos da expansão das relações de mercado, de relações financeiras menos reguladas e da própria globalização nas economias mais desenvolvidas e o retorno do mundo desenvolvido a uma economia de baixo crescimento, tal como demonstrado em Piketty (2014). As curvas das ditaduras não transicionais também apresentam um forte crescimento da 
desigualdade entre 1985 e 1990 e se estabiliza nos anos seguintes. Esse crescimento não pode ser explicado apenas pelos efeitos do fim do mundo comunista, uma vez que nos dados de 1985 só a Alemanha Oriental conta como regime comunista que deixa de existir nos dados do quinquênio que começa em $1990^{81}$. Mas fica claro que a tendência de crescimento da desigualdade nas ditaduras não transicionais é menor do que nas democracias não transicionais.

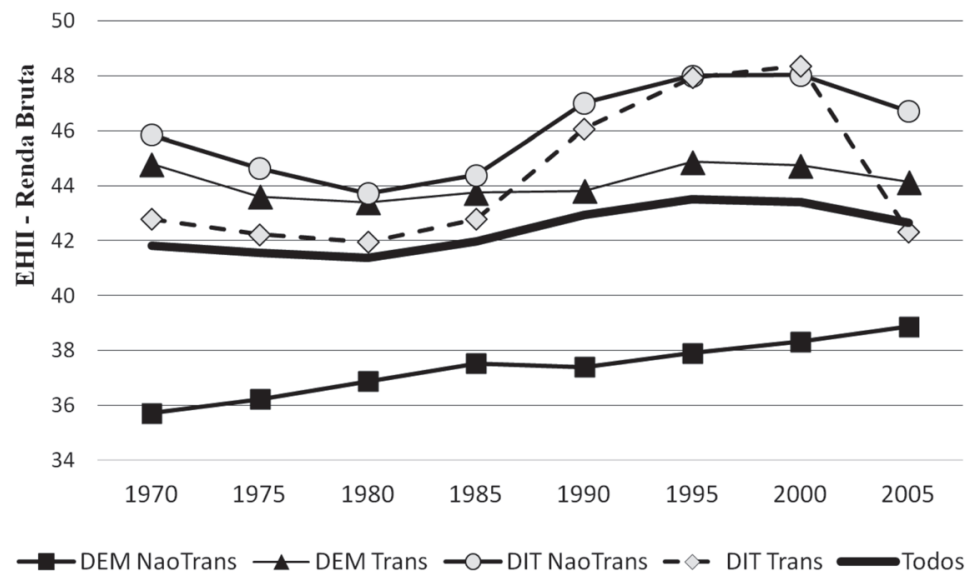

Gráfico 6 - Médias de Desigualdade GINI ao longo dos anos em quinquênios (EHII_bruto) Fonte: CGV, UTIP-EHII

Por sua vez, as ditaduras transicionais apresentam um pico de desigualdade próximo do quinquênio do ano 2000 e uma profunda queda no momento seguinte, o que é explicado facilmente pelo número de países-anos contidos nos dois

${ }^{81}$ Sem a Alemanha Oriental a média de 1985 cresce apenas de um GINI de 44.40 para um GINI de 45.42 
intervalos, que despenca de 24 para apenas 7 casos, todos de apenas 3 países: Nepal, Paquistão e Tailândia ${ }^{82}$. Ademais, o crescimento da desigualdade nas ditaduras transicionais após a década de 1990 é facilmente explicado pela transição dos regimes comunistas no Leste Europeu e Ásia Central. Isto porque com a transição democrática nestes estados, os países ditatoriais mais iguais saem do grupo, aumentando a respectiva média ${ }^{83}$. Por sua vez as democracias transicionais apresentam uma tendência estável, indicando um pequeno crescimento da média de desigualdade apenas na década de 1990.

No Gráfico 7 apresentamos os dados de desigualdade econômica bruta mensurados pelo SWIID. Mais uma vez no eixo horizontal estão dispostos os quinquênios e no eixo vertical está o valor médio de GINI para cada um dos grupos. Mantemos a mesma disposição das 5 curvas e a mesma estrutura de informação. As quatro primeiras referem-se às democracias e ditaduras transicionais ou não e a quinta refere-se à evolução da desigualdade em toda a amostra. No gráfico parece existir uma maior divergência entre os regimes na década de 1970, enquanto nos últimos dois quinquênios as cinco curvas sinalizam uma convergência entre os valores de 41 a 44 pontos de GINI.

Diferentemente do gráfico anterior, todas as curvas desse gráfico indicam que ao longo do período houve uma

\footnotetext{
${ }^{82}$ Os 24 do caso anterior são de 9 países: Equador, Fiji, Geórgia, Quirguistão, Nepal, Paquistão, Peru, Sudão e Uganda.

${ }^{83}$ No quinquênio de 1990-94 apenas a Albânia, Geórgia, Quirguistão e Sérvia - Montenegro são ditaduras (num total de 6 países-anos com dados), enquanto no quinquênio de 1985-89 temos 21 países-anos com dados de Albânia, Bulgária, Tchecoslováquia, Hungria, Quirguistão, Polônia e România.
} 
diminuição, ainda que pequena, da desigualdade pelo mundo, o que é surpreendente dado o grande consenso a respeito de que desde a década de 1970 assistiríamos a um retorno inexorável da desigualdade econômica, sobretudo nas sociedades mais desenvolvidas, com o avanço da economia de mercado e da globalização econômica.

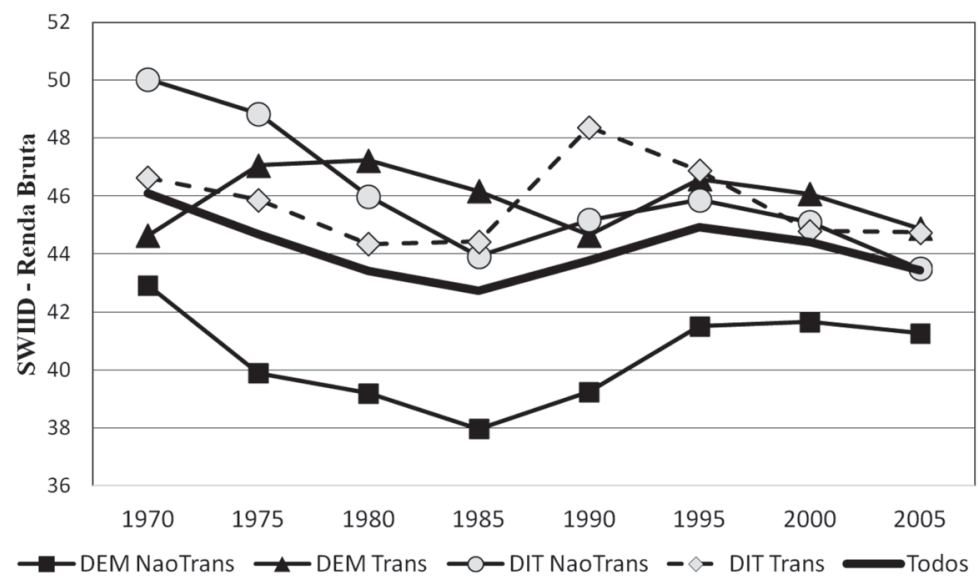

Gráfico 7 - Médias de Desigualdade GINI ao longo dos anos em quinquênios (SWIID_bruto) Fonte: CGV, SWIID

Por outro lado, a curva das democracias mais consolidadas (que não são as transicionais) tem um formato de $\mathrm{U}$ no qual o momento de menor desigualdade foi o quinquênio de 1985, ainda que a desigualdade da década de 1990 seja menor do que a encontrada na década de 1970. Ademais as outras três curvas parecem indicar uma tendência a redução da desigualdade no período indicado, mesmo que os movimentos das três tenham sido marcados por choques e picos, como, por exemplo, o auge da desigualdade em ditaduras transicionais 
no quinquênio dos anos 1990 (que é explicado pelo mesmo fenômeno apresentado na nota de rodapé 82).

Mais uma vez, os resultados preliminares indicam que a análise de dados sobre a desigualdade não é um empreendimento fácil. Mesmo partindo de um mesmo conjunto de informações compiladas pela UNU-WIDER, mas com metodologias de padronização dos dados diferentes, os dados indicam tendências da evolução da desigualdade discrepantes. Os padrões apresentados pelos dados de EHII parecem mais próximos dos debates contemporâneos ao apontarem que nas últimas décadas houve aumento da desigualdade econômica nas democracias e ditaduras não transicionais, fruto de hipotéticos efeitos das relações de mercado com a concomitante liberalização do setor financeiro e queda dos regimes comunistas. Por outro lado, não podemos negar o fato que este debate está voltado para as realidades econômicas dos países mais desenvolvidos, que nos gráficos 6 e 7 tendem a estar concentrados na curva de democracias mais consolidadas (não transicionais) e que apresentaram, pelo menos a partir de 1985, crescimento da desigualdade econômica, inclusive nos dados do SWIID. E os movimentos da desigualdade fora dessa região geográfico-econômica tendem a ser menos discutidos pela literatura devido a pouca disponibilidade de dados.

\section{¿ִ}

Como os dados ao longo dos anos são menos informativos para a análise dos efeitos da democracia sobre a desigualdade em países que transitam de um regime político para o outro, propomos uma nova forma de verificar a dinâmica temporal destes. Observamos agora a evolução da desigualdade 
econômica segundo o horizonte de democratização, que é definido de acordo com a persistência do regime democrático no tempo. Inaugurado após uma transição, a democracia perdura até atingirmos o ano de 2008 (ano final para o qual temos dados) ou até acontecer uma nova transição que reverta o regime político do país.

Visando facilitar a comparação entre democracia e desigualdade econômica, incluímos também valores negativos no horizonte de democratização. Damos o valor de -1 ao ano imediatamente anterior à transição democrática e assim continuamente, até atingirmos uma transição anterior no tempo ou chegarmos ao ano de entrada do país na amostra (sendo o limite o ano de 1960). É importante salientar que as dinâmicas do lado esquerdo dos gráficos sobre os horizontes de democratização referem-se, portanto, à relação entre desigualdade econômica e o regime anterior à transição e no lado direito a evolução da desigualdade no imediato à transição política e durante o decorrer do regime democrático instaurado.

Assim definimos como 0 (zero) o momento no qual um país se democratiza ou se torna um regime autoritário e como +1 o primeiro ano daquele governo (ou seja, nenhum ano/país recebe o valor de zero nesta mensuração). Os números positivos indicam o avanço no tempo da democracia. Por exemplo, como em nosso banco o Brasil se democratizou em 1985, o ano de 1975 recebe o valor de -10 e o ano de 1994 recebe o valor de +10 . Restringimos a análise apenas para os países que fizeram uma transição política. Isto é as democracias e ditaduras transicionais. Optamos por deixar de fora da análise as democracias não transicionais, pois não temos dados sobre desigualdade para o período autoritário anterior a estas transições. 
Nos Gráficos 8 a 10 apresentamos essa relação, plotando no eixo vertical os valores médios de EHII e de SWIID e no eixo horizontal os valores do horizonte de democratização. No Gráfico 8 mensuramos o horizonte de democratização anualmente, no 9 trienalmente e no 10 por décadas. Optamos por utilizar intervalos de tempo mais amplos para reduzir eventuais problemas causados por dados faltantes. As informações mais importantes são as mais próximas da transição democrática, por três motivos: a) após certo intervalo de tempo, características próprias do regime podem parar de produzir os efeitos sobre a desigualdade se houver retornos decrescentes; $b$ ) quanto mais se distancia do momento da transição democrática, menor é o número de anos-países que compõe a média de desigualdade naquele ponto do horizonte de democratização; e c) os efeitos da desigualdade sobre a democracia podem ser observados no imediato anterior à transição política.

Apresentamos os efeitos dos regimes políticos 20 anos antes e 20 anos depois da transição democrática. Para a construção da curva do efeito do horizonte de democratização sobre EHII, temos em média 45 anos-países para os primeiros 5 anos democráticos, 38 para o quinquênio seguinte, 33 para o período entre 10 e 15 anos pós democratização e, por fim, 26 no último quinquênio. Em SWIID os números são, respectivamente, $55,47,40$ e 32. E nos anos anteriores à democratização temos em EHII 48, 40, 30 e 23 anos-países e para o SWIID temos 49, 37, 24 e 17; todos listados em ordem cronológica inversa e que demonstram claramente a maior confiabilidade dos dados nos arredores da transição política. 


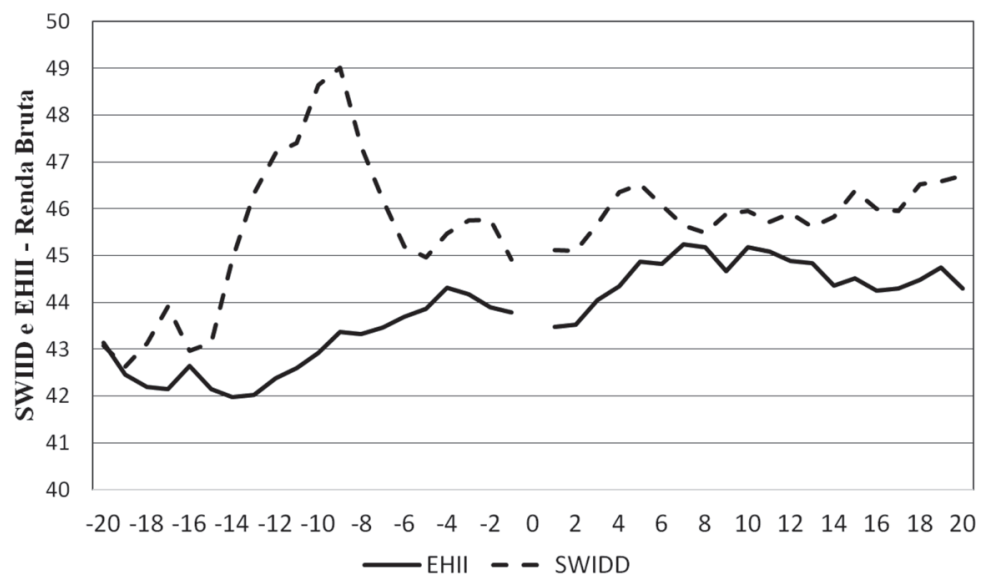

Gráfico 8 - Médias de desigualdade GINI ao longo do horizonte democrático (EHII e SWIID) - anual Fonte: CGV, UTIP-EHII, SWIID

No Gráfico 8 apresentamos a média de desigualdade econômica entre todos os países que passaram por alguma transição entre 1960 e 2008. O intervalo vazio no meio do gráfico refere-se ao momento da transição e tem a função de deixar devidamente separado o período ditatorial (esquerda) do democrático (direita). A primeira conclusão é que o tipo de regime político não tem efeitos nas duas curvas do EHII e do SWIID. Os dados descritivos demonstram a existência de uma leve tendência de crescimento de desigualdade ao longo do horizonte democrático, mas cuja inclinação independe do regime político ser autoritário ou democrático. O único grande choque encontrado é o pico que existe próximo ao nono ano anterior à transição na curva de SWIID, que é reduzido ao adotarmos intervalos de tempo maiores no eixo do horizonte de democratização. 
Fazemos isto no Gráfico 9, no qual apresentamos o mesmo horizonte democrático, mas agora no eixo horizontal estão triênios e não mais anos anteriores e posteriores à transição democrática. Os intervalos de tempo maiores minimizam potenciais distorções causadas por dados faltantes de certos países. O resultado é assaz semelhante ao anterior. $\mathrm{Na}$ série dos dados de EHII não há nenhuma mudança estrutural com a alternância de regime. O crescimento visto no momento posterior à transição democrática é o mesmo que já acontecia nos triênios anteriores. Já nos dados de SWIID esse efeito não é aparente, pois há uma importante queda da média da desigualdade entre o quarto e o segundo triênio anterior à democratização, embora no período democrático a tendência seja de um crescimento leve da desigualdade. Contudo, fora este choque, existe uma tendência crescente em toda a série que independe do regime político.

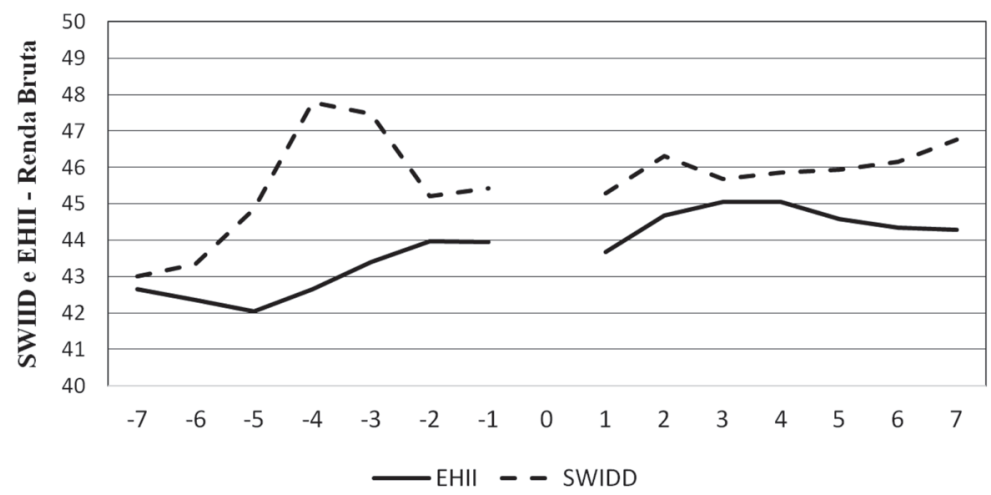

Gráfico 9 - Médias de desigualdade GINI ao longo do horizonte democrático (EHII e SWIID) Fonte: CGV, UTIP-EHII, SWIID 


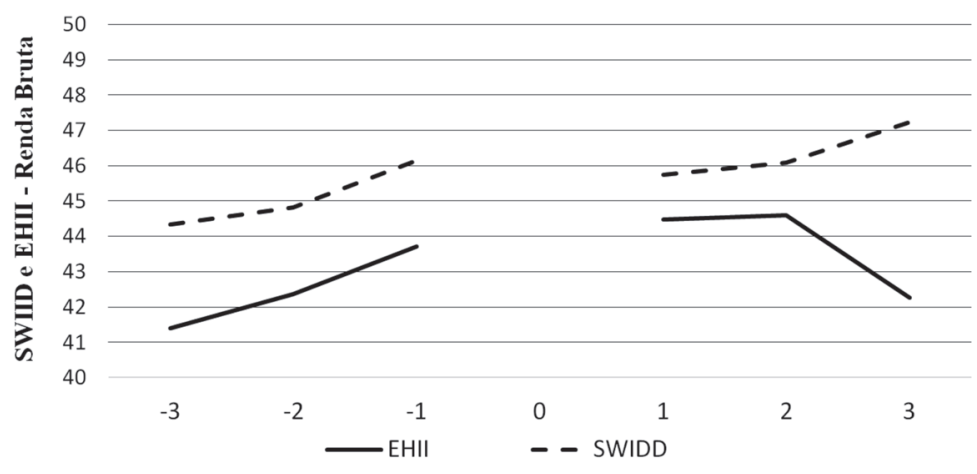

Gráfico 10 - Médias de desigualdade GINI ao longo do horizonte democrático (EHII e SWIID) - por décadas Fonte: CGV, UTIP-EHII, SWIID

Por fim, no Gráfico 10 apresentamos o mesmo horizonte democrático, tendo como unidade temporal décadas. Os resultados são mais uma vez semelhantes aos anteriores, com exceção apenas do fato de que com os dados de EHII existe uma aparente queda da desigualdade a partir da segunda década democrática, o que pode indicar que os efeitos da democracia sobre a desigualdade não são imediatos, mas sim resultados do acúmulo de práticas da experiência democrática. Tal hipótese foi advogada e testada com razoável sucesso por Muller (1998).

Contudo, na série de SWIID este mesmo padrão não se repete, mas pelo contrário, na terceira década há um aparente crescimento da desigualdade econômica e não arrefecimento do processo, indicando de fato que há uma trajetória de crescimento da desigualdade com o passar dos anos que é completamente independente do regime político em questão.

Podemos concluir, tendo como base os dados apresentados nos gráficos 6 a 10, que a democracia não parece ser um redutor da desigualdade econômica. Os padrões observados 
até agora não indicam um efeito distinto da democracia em relação às ditaduras sobre a desigualdade. $\mathrm{E}$ a principal diferença encontrada no Gráfico 5 entre democracias e ditaduras não transicionais parece ser mais resultado do fato de que as democracias não transicionais existem em sociedades menos desiguais do que algum efeito específico destes próprios regimes políticos. A análise da dinâmica temporal feita nos 38 anos entre 1970 e 2008 , inclusive indica um crescimento efetivo da desigualdade entre as democracias não transicionais. E os dados das democracias transicionais parecem demonstrar por outro lado a inexistência de uma relação entre democracia e desigualdade. Os gráficos 8 a 10 indicam claramente que a transição democrática não afetou o comportamento da desigualdade econômica ao longo do contínuo do horizonte de democratização.

Por outro lado, tal como em toda a literatura apresentada no capítulo 1, estes dados partem de um suposto forte e que deve e será equacionado no próximo capítulo. Ao longo de toda a seção trabalhamos com a ideia de que existe um efeito médio e negativo da democracia sobre a desigualdade. Com o tipo de dado e métodos rudimentares aqui utilizados, não é possível separar os efeitos da democracia em sociedades mais desiguais dos efeitos da democracia em sociedades menos desiguais. Ao longo de todos os gráficos que analisaram conjuntamente as variáveis de regime político e desigualdade econômica, trabalhamos essencialmente com o conceito de média.

Por fim, antes de iniciarmos a análise inferencial da nossa hipótese, desenvolvida no capítulo 4 , avançaremos um pouco mais sobre a relação descritiva entre democracia e desigualdade e mostramos na próxima seção qual é o comportamento das duas variáveis numa visão de longo prazo e que abrange os 
dois últimos séculos, abrindo espaço para análise de como o processo de democratização das democracias mais antigas, e hoje consideradas como regimes políticos democráticos mais consolidados, afetou a desigualdade econômica.

\subsection{Democracia e desigualdade - visão de longo prazo}

Nesta seção apresentamos as mesmas estatísticas descritivas da seção anterior a partir de outro banco de dados que contém informações que começam no século XIX (1820) e se estendem até 1992. Uma questão a respeito destes dados é que o esforço de obtenção de uma série mais longa de desigualdade tem como preço uma medida que é menos confiável e que abrange um menor número de países. Contudo, o exercício é válido, pois introduz na análise a democratização dos países desenvolvidos da Europa Ocidental, América do Norte e Oceania, o que não é captado pelos anteriores.

Os dados que permitem esta visão de longo prazo da desigualdade foram elaborados por Ansell e Samuels (2010), a partir de informações organizadas por Bourguignon e Morrisson - BM (2002), cobrindo cerca 53 países em intervalos de 20 anos entre 1820 e 1950 e em intervalos de 10 anos entre 1950 e $1992^{84}$. Estes autores estimaram a parcela da renda tomada por cada decil da distribuição de renda em cada um dos países com o objetivo de estimar a evolução da desigualdade em todo o mundo durante os dois últimos séculos. A partir destes dados dos decis da distribuição de renda,

\footnotetext{
${ }^{84}$ Agradecemos a gentileza dos professores Ben Ansell e David Samuels por terem nos fornecido os dados de GINI - BM utilizados em seu trabalho.
} 
Ansell e Samuels calcularam o coeficiente de GINI de cada um destes países em cada um dos intervalos, interpolando linearmente os dados em cada período para ter como unidade básica o país-ano. Segundo os autores, apesar de todos os problemas, os dados do BM são os únicos disponíveis para mensurar a desigualdade antes de 1945 e são amplamente citados na literatura ${ }^{85}$.

O primeiro problema decorre do fato que as estimativas são tomadas somente a intervalos de 10 ou 20 anos e Ansell e Samuels organizam os dados por países-anos. Além disto, as estimativas de alguns países são partilhadas com outros que possuem estruturas econômicas semelhantes. Por exemplo, certos pontos de dados da Irlanda são derivados da Grã Bretanha, Portugal e Espanha partilham do mesmo dado, assim como os países escandinavos. De acordo com Bourguignon e Morrisson (2002), o agrupamento foi baseado em considerações de consistência histórica e homogeneidade. Existem de fato apenas 16 estados $^{86}$ que estão listados individualmente num total de 33 grupos mensurados. Além desses 16 países, existem mais 17 grupos de mais de um país que são compilados por Bourguignon e Morrisson como fossem uma única estrutura econômica autônoma ${ }^{87}$. Por fim, como terceiro

${ }^{85}$ O artigo de Bourguignon e Morrisson (2002) possui 1384 citações no Google Scholar. Acesso em: 16 nov. 2016.

${ }^{86}$ Os 16 países são: Egito, Nigéria, África do Sul, China, Índia, Indonésia, Japão, Brasil, México, Polônia, Rússia, Turquia, França, Alemanha, Itália, Estados Unidos. Todos possuem no mínimo $1 \%$ da população mundial.

${ }^{87}$ Os outros 17 grupos são i) Costa do Marfim, Gana e Quênia; ii) África do Norte; iii) outros países africanos; iv) Burma, Bangladesh e Paquistão; v) Tailândia e Filipinas; vi) 45 países asiáticos; vii) Coréia do Sul e Taiwan; viii) Colômbia, Peru e Venezuela; ix) Argentina e Chile; x) 37 países latino americanos; xi) Portugal e Espanha; xii) Bulgária, Grécia, Romênia e Iugoslávia; xiii) Austrália, Canadá e Nova Zelândia; xiv) Áustria, Tchecoslováquia e Hungria; 
e último problema a variação geográfica dos dados é menor do que nos outros bancos: $52 \%$ dos países-anos pertencem a nações da Europa Ocidental ou do Leste Europeu e ex-URSS, $23 \%$ das Américas, $14 \%$ da Ásia, 3.5\% da Oceania e apenas $8 \%$ da África.

Para medir os regimes democráticos, fizemos uma combinação dos indicadores sobre características institucionais e competitivas dos regimes políticos. A primeira é o indicador dicotômico de Boix e Rosato (2001) - BR que classifica, desde 1820, como democráticos os países que possuem: i) legislativo eleito em eleições livres e com vários partidos; ii) executivo eleito direta ou indiretamente pelo voto popular e respondendo diretamente aos eleitores ou à legislatura popularmente eleita; iii) participação (direito ao voto) de no mínimo 50\% da população adulta masculina. O trabalho de Boix e Rosato (2001) estendeu o banco CGV para o período anterior à $2^{\mathrm{a}}$ Guerra Mundial, adotando um critério empírico um pouco menos exigente, mas partindo de uma mesma concepção minimalista e procedimental de democracia (BOIX; ROSATO, 2001; BOIX; MILLER; ROSATO, 2012).

A seguir, incorporamos as informações compiladas por Przeworski (2009), que indicam qual é a extensão legal do direito ao voto em cada país. O banco de dados estendido com informações sobre as instituições e alguns eventos políticos ocorridos desde o estabelecimento das primeiras instituições representativas modernas pode ser visto em Przeworski (2011b). Consideramos como democráticos apenas aqueles

xv) Escandinávia; xvi) Suíça, Beneluz e microestados europeus; e xvii) Reino Unido e Irlanda. 
regimes que simultaneamente foram considerados democráticos por Boix e Rosato (2001) e para o quais Przeworski (2009) indica a existência de sufrágio universal legal para todos os homens. Por fim, como critério adicional consideramos autoritários todos os países que permitiam a existência legal da escravidão.

Para o funcionamento adequado da hipótese dos efeitos heterogêneos da democracia é necessário a efetiva realização do sufrágio universal, uma vez que em geral as regras que excluem alguma parte do eleitorado, sejam elas censitárias ou requisitos educacionais, tendem a excluir justamente o segmento menos favorecido da sociedade. $\mathrm{O}$ caso brasileiro a respeito da impossibilidade do voto do analfabeto até 1985 é exemplo ilustre desse fato. Posto isto, optamos por incorporar na definição de democracia o requisito do sufrágio universal masculino. Uma melhor identificação de real democracia seria por meio da avaliação do exercício efetivo do direito ao voto. Contudo como não encontramos nenhum autor que tenha mensurado tal elemento, optamos por considerar suficiente o direito legalmente estabelecido do sufrágio universal a todos os homens.

As principais estatísticas descritivas do GINI-BM são apresentadas na Tabela 6 e sua densidade de kernel no Gráfico 11. Em ambas as figuras apresentamos as informações para toda a amostra e também para cada regime político. Mais uma vez estendemos os valores do GINI para um intervalo entre $0 \mathrm{e}$ 100 pelas mesmas razões apresentadas anteriormente.

$\mathrm{Na}$ Tabela 6, as democracias mais uma vez possuem uma média e mediana de desigualdade econômica inferior às das ditaduras. Outra constatação é que o número de anos-países ditatoriais é duas vezes superior ao número de anos-países 
democráticos, o que é esperado, uma vez que a primeira experiência democrática só ocorre em 1850 e só a partir de 1864 existem países que permanecem como democracia por longos períodos de tempo. E as curvas de distribuição também são um pouco diferentes em relação à curtose e à assimetria, o que fica bem claro no Gráfico 11 onde apresentamos as densidades de kernel da desigualdade econômica em toda a amostra e para as democracias e ditaduras separadamente. Comparando com os dois gráficos de densidades apresentados anteriormente, fica patente como os dados do BM mostram um comportamento mais discrepante entre as curvas de desigualdade em democracias e em ditaduras.

Tabela 6 - Dados descritivos de GINI - BM

\begin{tabular}{lccc}
\hline & Toda amostra & Democracias & Ditaduras \\
\hline Média & 45.02 & 41.73 & 46.67 \\
Desvio Padrão & 6.48 & 5.97 & 6.09 \\
Mediana & 44.94 & 40.60 & 46.67 \\
Assimetria & -0.28 & 0.34 & -0.65 \\
Curtose & 2.97 & 3.00 & 4.05 \\
Mínimo & 27.66 & 27.66 & 27.66 \\
Máximo & 62.04 & 55.72 & 62.04 \\
Número de Observações & 5718 & 1905 & 3813 \\
\hline
\end{tabular}

Observação 1: 83 países-anos ditatoriais são mais desiguais que todos os países-anos democráticos: todos pertencentes à África do Sul de 1910 a 1992.

Fonte: BM-GINI

Nestes novos dados que possibilitam uma visão de longo prazo da desigualdade, há uma concentração maior da distribuição de GINI para democracias à esquerda, enquanto para as ditaduras a concentração está mais à direita. A distribuição de $\mathrm{BM}$ em ditaduras tem um formato trimodal com os três 
vértices localizados entre os GINIs de 45 e 55. Já a distribuição de $\mathrm{BM}$ em democracias é unimodal com um único vértice em torno de 40. Por outro lado, são bastante semelhantes os desvios padrões das duas distribuições, assim como os mínimos, máximos e a própria amplitude total.

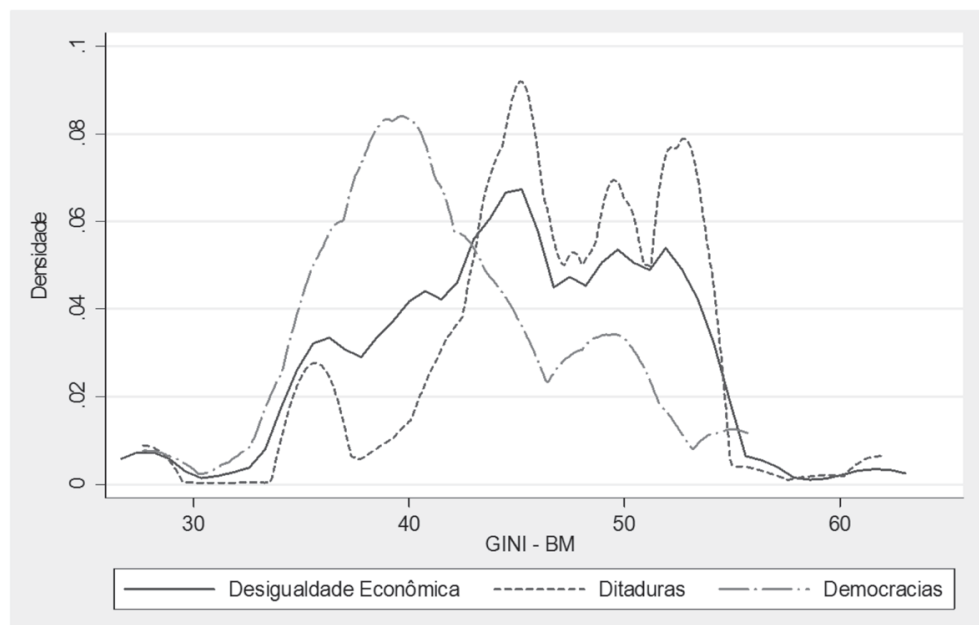

Gráfico 11 - Densidades de Kernel de desigualdade econômica de longo prazo (BM) por regimes politicos Fonte: BM-GINI

No Gráfico 12 (p. 166) apresentamos a evolução da média de desigualdade ao longo do tempo - desde 1820 até 1992 - para toda a amostra, para as ditaduras e para as democracias. Obviamente o número de pontos de dados é bem menor nos primeiros anos da amostra. De 1820 a 1849 são apenas 17 casos, entre 1850 e 1870 são 26 casos, 40 casos a partir de 1930 até o máximo de 49 casos em 1992. Há um primeiro episódio democrático apenas em 1848-49 e 1851 na França, mas de fato a primeira democracia surge apenas em 1864 (Grécia), a 
segunda em 1865 (EUA), a terceira em 1870 (Nova Zelândia), a França novamente em 1870 e assim por diante. Somente em 1910 temos mais de 10 democracias e só depois de 1950 mais de 20. Visando maximizar a informação contida nos dados, o Gráfico 12 tem como unidade de análise a média de desigualdade por décadas desde 1820 até 1990 e por tipo de regime político. No eixo vertical, como nos outros gráficos, estão os valores médios de GINI e no eixo horizontal as décadas.

O Gráfico 12 apresenta um padrão bem interessante. Enquanto no século XIX não há diferenças gritantes entre a média da desigualdade nas democracias e nas ditaduras, após a $1^{\text {a }}$ Guerra Mundial há um forte aumento na distância entre as duas curvas, que se mantém bastante parecido até o final da década de 1950 (mesmo que durante esse período ambas apresentem uma tendência declinante bastante relevante). A diferença entre as duas médias na primeira década do século XX é de apenas 1.1 pontos de GINI, enquanto que em 1950 essa diferença sobe para 4.6 pontos. Esse diferencial é um pouco reduzido entre as décadas de 1960 e 1970, e em 1980 a diferença é de apenas 3.2 pontos de GINI. E apenas no último ponto de dado, a média do triênio 1990-1992, a divergência entre democracias e ditadura cresce abruptamente para 8.5 pontos de GINI.

Este período entre 1900 e 1950 também é analisado por Thomas Pikkety (2014) como um momento no qual há uma enorme queda da desigualdade nas economias mais desenvolvidas da Europa. Para o economista, as principais causas subjacentes a este forte processo redutor da desigualdade foram os esforços de mobilização nacional nas duas Grandes Guerras, que tiveram entre suas consequências a destruição parcial do estoque de capital das elites econômicas por meio do próprio 
conflito ou como fonte de financiamento do estado, a prolongada crise da Grande Depressão, a perda do valor dos títulos da dívida pública com o surgimento de economias inflacionárias e o próprio processo de descolonização da África e Ásia, com o qual parte dos ativos estrangeiros europeus evaporaram.

Por fim, repetindo a análise feita na seção anterior, apresentamos no Gráfico 13 a evolução da desigualdade econômica segundo o horizonte de democratização. Definimos horizonte de democratização da mesma forma: a persistência do regime no tempo. Inaugurado após uma transição democrática e perdurando até atingirmos o ano de 1992 ou até acontecer uma nova transição que reverta o regime político do país. $\mathrm{O} 0$ (zero) determina o momento no qual um país se democratiza e como +1 o primeiro ano terminado naquele governo (ou seja, nenhum ano-país recebe o valor de zero nesta mensuração). Os números positivos indicam sempre o avanço no tempo da democracia, enquanto os números negativos referem-se ao período autoritário anterior a uma transição democrática. O gráfico apresenta a média da desigualdade nos regimes autoritários nos 30 anos anteriores à democratização (esquerda do gráfico) e nos trinta anos democráticos posteriores (direita) ${ }^{88}$.

\footnotetext{
${ }^{88}$ Visando facilitar a comparação entre democracia e desigualdade econômica, incluímos também valores negativos no horizonte de democracia. Damos o valor de - 1 ao ano imediatamente anterior à transição democrática e assim continuamente, até atingirmos uma transição anterior no tempo ou chegarmos ao ano de entrada do país na amostra. As dinâmicas do lado esquerdo dos gráficos sobre os horizontes de democracia se referem, portanto, à relação entre desigualdade econômica e o regime anterior à transição e no lado direito a evolução da desigualdade no imediato à transição política e durante o regime democrático instaurado.
} 


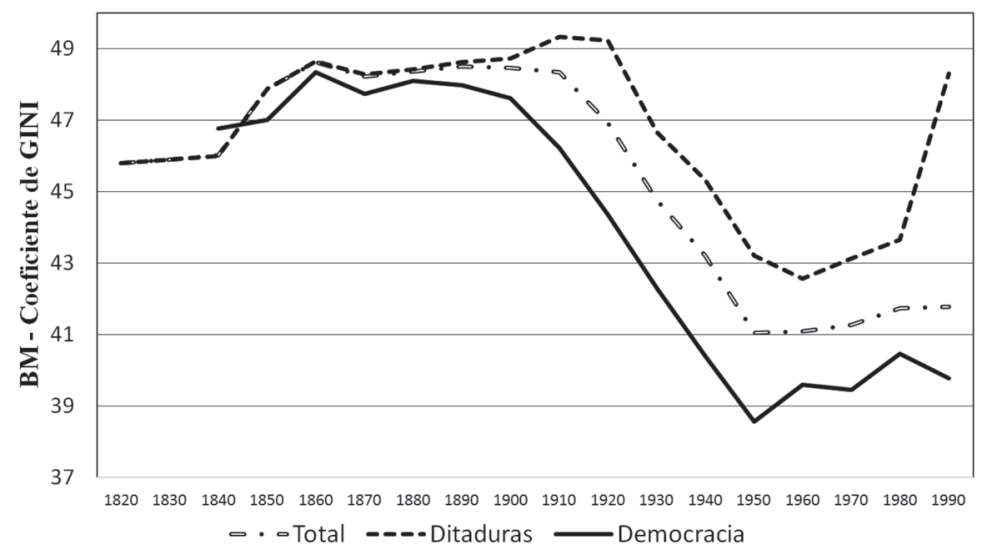

Gráfico 12 - Médias de desigualdade GINI (BM) por décadas e por regime político Fonte: BOIX-ROSATO e BM-GINI

O Gráfico 13 demonstra um padrão extremamente interessante de evolução da desigualdade segundo o horizonte de democratização. Entre os trigésimo e vigésimo anos autoritários anteriores à democratização (assinalada pelo ano 0), não há alteração no nível de desigualdade econômica. Já nos dez últimos anos do regime autoritário, há o início de um processo de redução da desigualdade que se estende até o vigésimo ano pós-democratização, mesmo que nos primeiros anos após a transição democrática exista um pico de aumento da desigualdade que depois é rapidamente revertido. Isto é, a própria transição democrática não parece afetar a média da desigualdade e nem a sua tendência de evolução. A principal constatação é que já no período anterior à transição, os países entram em um processo de redução da desigualdade que se estende no posterior da transição política e durante a própria 
consolidação da democracia, se estabilizando somente a partir do vigésimo ano democrático ${ }^{89}$.

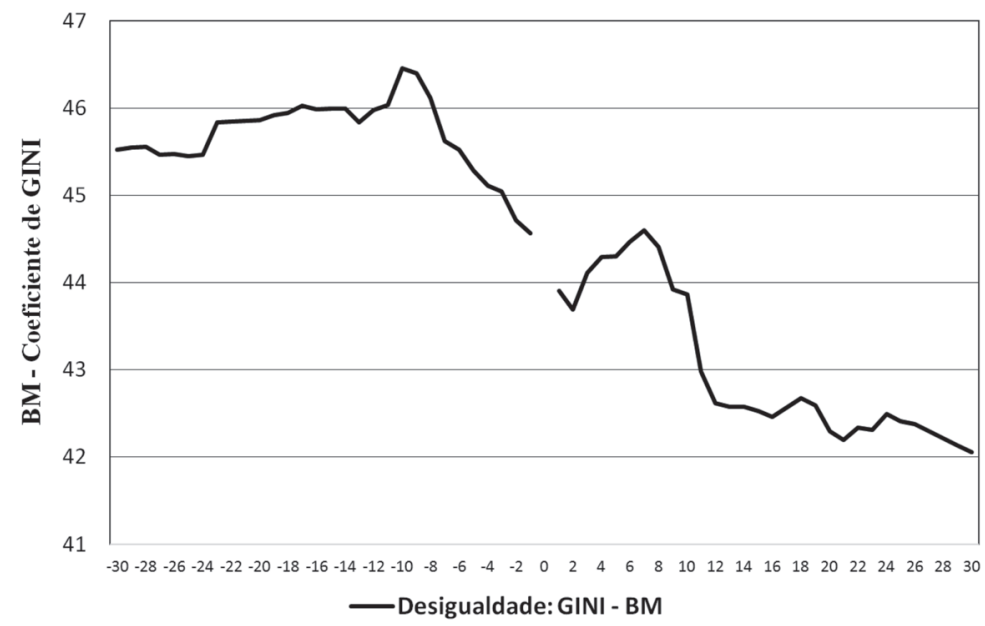

Gráfico 13 - Médias de desigualdade GINI (BM) ao longo do horizonte democrático - visão de longo prazo Fonte: BOIX-ROSATO e BM-GINI

Interessante apontar que esta possível interpretação dos dados expostos no Gráfico 13 contraria à tese de Ansell e Samuels (2010 e 2014). O argumento defendido por Ansell e Samuels parte da teorização de que a democratização decorre do surgimento de uma elite econômica e mesmo de uma classe média autônoma do Estado, que demandam proteção contra o poder expropriativo do Leviatã absolutista. Isto implicaria, do ponto de vista empírico, que há uma associação entre o crescimento da desigualdade e um concomitante aumento da probabilidade de democratização. E isto não é o que parece ocor-

${ }^{89}$ Consolidação entendida simplesmente como a persistência no tempo do regime democrático. 
rer nos dados do Gráfico 13 nos anos anteriores à transição democrática. A tendência apresentada no imediato anterior à transição democrática é nitidamente crescente e persiste após a mudança de regime político.

Obviamente não temos a pretensão de resolver este impasse teórico com uma análise puramente descritiva. Conforme já exposto ao longo do texto existe uma miríade de fatores de confusão que permeiam a relação entre democracia e desigualdade. Contudo, é interessante notar como a relação de longo prazo entre desigualdade e democracia parece tomar uma perspectiva bastante distinta daquela encontrada no período entre 1960 e 2010. Desta forma, após testarmos a hipótese sobre a heterogeneidade dos efeitos da democracia sobre a desigualdade nos dados mais refinados e confiáveis da $2^{\text {a }}$ metade do século XX, verificaremos se esta hipótese encontra respaldo empírico em uma visão de maior longo prazo, ainda que mais restrita geograficamente.

\subsection{Variáveis de controle}

Como apresentamos no último parágrafo, a relação entre democracia e desigualdade é permeada por outros fatores que a afetam simultaneamente. Desta maneira, não podemos realizar nenhuma afirmação conclusiva a respeito de algum tipo de relação causal entre as duas variáveis com os dados descritivos expostos ao longo desse Capítulo 3, sem que esses possíveis fatores de confusão sejam controlados. Variáveis e fatores como o grau liberalização dos mercados, a globalização, o capital humano e também o nível de desenvolvimento 
de cada país podem desempenhar um papel relevante e tornar espúrias algumas das relações encontradas.

Tomando como ponto de partida as contribuições da literatura recente, iremos controlar a análise para quatro conjuntos de variáveis, que mensuram: os processos de liberalização e expansão das relações de mercado i) no nível do país e ii) em nível global; iii) o nível de desenvolvimento econômico de cada país e, por fim, iv) o nível educacional da população como proxy do capital humano e da distribuição das habilidades presente no sistema econômico daquela sociedade.

Conforme já exposto anteriormente, é de fundamental importância controlar para os fatores de mercado uma vez que democracia e mercados tendem a andar juntos no mundo contemporâneo. Ainda mais depois do fim da guerra fria e da terceira onda de democratização, quando vigora um processo distinto, mas concomitante da expansão de regimes políticos democráticos e disseminação de processos econômicos liberalizantes em temas de comércio exterior e das próprias relações econômicas nacionais.

Como esses dois processos ocorrem ao mesmo tempo é bastante provável que os reais efeitos da democracia sobre a desigualdade sejam mitigados pelos efeitos causados por relações econômicas menos reguladas. Do mero fato que um país se democratiza e apresenta dados crescentes de desigualdade não decorre que a democracia não seja uma força equalizadora da sociedade, é possível que a democracia esteja reduzindo a velocidade do aumento da desigualdade que o processo de expansão das relações de mercado impõe.

Os processos de democratização política e liberalização econômica, embora concomitantes, são independentes. 
A história chilena ilustra bem esse fato. Antes do golpe comandado pelo general Augusto Pinochet, o então presidente Salvador Allende, que havia sido eleito democraticamente, estava direcionando a política econômica chilena para um ponto distante dos mercados. E depois de 1973, o regime militar de Pinochet colocou o Chile no caminho da liberalização econômica em um momento em que não havia mais liberdade política. Posto de outra forma, a liberdade política não é equivalente à liberdade de comprar (GALBRAITH, 2008).

Desta forma, iremos controlar nossa análise para quatro variáveis que buscam capitar os processos de mercado:

\section{a) Processos de Mercado dentro do país}

i. Abertura Econômica: Volume total de comércio (exportação e importação) como percentagem do PIB a preços constantes. Dados da Penn World Tables versão 7.1 (HESTON; SUMMERS; ATEN, 2012).

ii. Participação do Governo: Proporção dos gastos do governo em relação ao PIB a preços constantes. Dados da Penn World Tables version 7.1 (HESTON; SUMMERS; ATEN, 2012).

b) Globalização: processos de Mercado em escala global

iii. Comércio Mundial: Log (Soma de todas as correntes de importação e exportação em cada ano / 2). Dados da Penn World Tables version 7.1 (HESTON; SUMMERS; ATEN, 2012).

iv. Variável Binária como indicador do Período Pós Guerra Fria: 1 - depois de 1990; 0 - caso contrário. 
Também vamos controlar nossa análise para o nível de desenvolvimento de cada país, pois é amplamente reconhecido que o nível de desenvolvimento está altamente correlacionado com a democracia e também com a própria desigualdade, tal como proposto pela famosa curva de Kuznets (1955). Além disso, não podemos desconsiderar o fato de que os países desenvolvidos têm mais recursos para lidar com problemas decorrentes da desigualdade, uma vez que a questão da sobrevivência econômica e reprodução social das elites, classes médias e mesmo dos segmentos mais empobrecidos são conquistas já garantidas. Mensuraremos o nível de desenvolvimento de cada país por meio de suas variáveis: o PIB real per capita e o índice de urbanização.

v. Desenvolvimento: Log do PIB Real per capita em formato quadrático. Dados da Penn World Tables version 7.1 (Heston, Summers and Aten 2012).

vi. Urbanização: Porcentagem urbana da população total. Dados do Banco Mundial 2013. (WORLD BANK GROUP WDI, 2013).

Por fim, a disponibilidade de capital humano também pode afetar a relação entre democracia e desigualdade. Isto porque quanto mais bem educada e dotada de habilidades, mais recursos os indivíduos da sociedade possuem para superar os desafios econômicos impostos pela integração dos mercados e globalização, ao passo que também existe uma associação entre o nível educacional e o regime político: quanto mais qualificado é o demos de determinada sociedade, maior é sua capacidade de exigência de controle e responsividade das ações do governo. 
Desta forma, incluímos na especificação uma variável que mensura o nível de escolaridade médio da população.

vii.Escolarização: Escolaridade média da população adulta masculina com mais de 25 anos. Dados do Institute for Health Metrics and Evaluation (IHME) - University of Washington. (GAKIDOU et al., 2010; HOGAN et al., 2010; RAJARATNAM et al., 2010).

Na Tabela 7 abaixo apresentamos a estatística descritiva das variáveis de controle e a fonte de informação de onde obtivemos os dados. Com exceção da variável de globalização que é um indicador do período pós 1990 e da variável escolarização, todas as outras foram obtidas a partir das informações compiladas pelo Penn World Tables versão 7.1 (HESTON; SUMMERS; ATEN, 2012) e pelo Banco Mundial em sua série de indicadores (WORLD DEVELOPMENT INDICATORS - THE WORLD BANK, 2013). Por fim, os dados de educação foram elaborados pelo Institute for Health Metrics and Evaluation da Universidade de Washington (GAKIDOU et al., 2010; HOGAN et al., 2010; RAJARATNAM et al., 2010).

No próximo capítulo discutiremos a relação entre democracia e desigualdade em seus pormenores, incorporando os dados aqui apresentados à discussão teórica e metodológica sobre os efeitos heterogêneos da democracia ao longo dos diferentes pontos da distribuição de desigualdade econômica entre os países realizada no Capítulo 2 . 


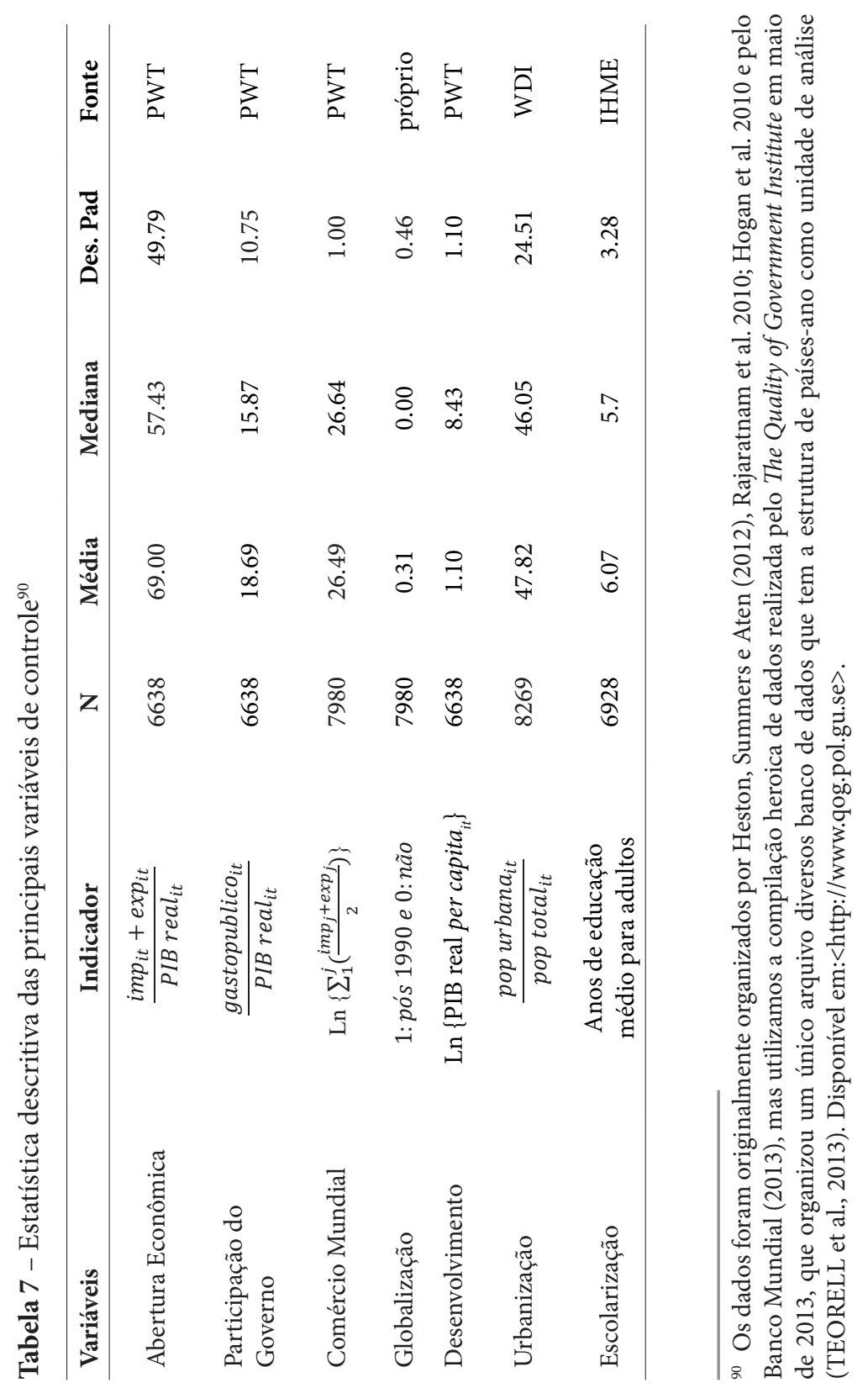

